\title{
La integración de cláusulas sociales, ambientales y de innovación en la contratación pública ${ }^{1}$
}

\author{
Isabel Gallego Córcoles \\ Universidad de Castilla-La Mancha \\ Isabel.Gallego@uclm.es
}

\begin{abstract}
NOTA BIOGRÁFICA
Isabel Gallego Córcoles es Doctora en Derecho por la UCLM, profesora titular de Derecho Administrativo en la Universidad de Castilla-La Mancha. Sus líneas de investigación prioritarias son la contratación pública, el derecho de aguas y las privaciones coactivas de la propiedad.
\end{abstract}

\section{SUMARIO}

1. ANTECEDENTES: LA PROGRESIVA CONSAGRACIÓN DE LA CONTRATACIÓN PÚBLICA COMO INSTRUMENTO AL SERVICIO DE POLITICAS AMBIENTALES, SOCIALES Y DE INNOVACIÓN. 2. EL CARÁCTER INSTRUMENTAL DE LA CONTRATACIÓN PÚBLICA COMO ELEMENTO ESTRUCTURANTE DE LA LCSP. LA PRECEPTIVA INCORPORACIÓN DE CLÁUSULAS SOCIALES Y AMBIENTALES EN TODO PROCEDIMENTO DE LICITACIÓN. 3. LA UTILIZACIÓN DE CLÁUSULAS AMBIENTALES, SOCIALES Y DE INNOVACIÓN COMO CRITERIOS DE ADJUDICACIÓN. 3.1. HACIA LA SUPERACIÓN DE LOS OBSTÁCULOS IMPUESTOS TRADICIONALMENTE POR EL DERECHO DE LA UNIÓN EUROPEA: LA RELAJACIÓN DE LA EXIGENCIA DE VINCULACIÓN CON EL OBJETO DEL CONTRATO. 3.2. LA REGULACIÓN DE LOS CRITERIOS DE ADJUDICACIÓN DE CARÁCTER ESTRATÉGICO EN LA LCSP. 3.3. LOS LÍMITES A LA INTRODUCCIÓN DE CONSIDERACIONES ESTRATÉGICAS COMO CRITERIOS DE ADJUDICACIÓN. 4. LA OBLIGADA INTRODUCCIÓN DE CONDICIONES DE EJECUCIÓN DE TIPO ESTRATÉGICO. 4.1. EXPERIENCIAS PREVIAS: LA DIFÍCIL INTELIGENCIA DE LOS LÍMITES IMPUESTOS POR EL DERECHO SOCIAL EUROPEO AL EMPLEO DE CONDICIONES DE EJECUCIÓN DE CARÁCTER SOCIAL. 4.2. LA NUEVA REGULACIÓN DE LA LCSP: LA OBLIGATORIEDAD DE INCLUIR EN CADA LICITACIÓN CONDICIONES DE EJECUCIÓN DE CARÁCTER ESTRATÉGICO. 5. LAS HERRAMIENTAS PROCEDIMENTALES AL SERVICIO DE LA INNOVACIÓN: EN ESPECIAL, LA ASOCIACIÓN PARA LA INNOVACIÓN. 6. NOTA FINAL: LA INCORPORACIÓN DE POLÍTICAS AMBIENTALES, SOCIALES Y DE INNOVACIÓN EN LA CONTRATACIÓN PÚBLICA: UN RETO QUE VA MÁS ALLA DE LO NORMATIVO.

\section{ANTECEDENTES: LA PROGRESIVA CONSAGRACIÓN DE LA CONTRATACIÓN PÚBLICA COMO INSTRUMENTO AL SERVICIO DE POLITICAS AMBIENTALES, SOCIALES Y DE INNOVACIÓN}

En la contratación pública late una indudable tensión entre el servicio al interés público y el principio de libre concurrencia. El Derecho español ha otorgado tradicionalmente una preponderancia casi absoluta al primero de los principios, mientras que el Derecho europeo se inclina decididamente a favor del segundo².

\footnotetext{
1 Este estudio se enmarca en el Proyecto de investigación concedido por Ministerio de Economía y Competitividad titulado "La nueva regulación de la contratación pública: Hacia un nuevo sistema de gobernanza pública y de actuación de los poderes públicos" DER2015-67102-C2-1-P.

2 Entre otros, MEILAN GIL J. L. (2013): "Las prerrogativas de la Administración en los contratos administrativos: propuesta de revisión", núm. 191, pág. 38. Vid. igualmente MORENO MOLINA J. A./PLEITE GUADAMILLAS F. (2009): La nueva Ley de Contratos del Sector Público. Estudio sistemático, 2. ed., 2009, pág. 63 y ss.
} 
Todo ello ha implicado una honda transformación en el instituto de la contratación pública que ha conducido a un sustancial vaciamiento de las prerrogativas administrativas, elemento tradicionalmente definitorio del contrato administrativo. Sin embargo, esta evolución no implica que el servicio al interés general quede reducido a su mínima expresión, realizado únicamente a través de la consecución de la libre competencia. Los intereses generales vuelven a teñir la contratación una vez que se reconoce el valor de ésta como instrumento para la consecución de distintos mandatos y principios constitucionales (art. 1.1, art. 45 CE entre otros) y de diversas políticas públicas.

La contratación pública no puede concebirse exclusivamente como una herramienta de aprovisionamiento de los poderes públicos, sino como un poderoso instrumento para llevar a cabo políticas públicas tan diversas como la promoción de la innovación, el fomento de las Pymes o la sostenibilidad social y ambiental $^{3}$. En este sentido, debe advertirse que tomando en consideración solamente las cifras relativas a la adjudicación de obras, suministros y servicios, la contratación pública supone aproximadamente el $14 \%$ del PIB de la Unión Europea ${ }^{4}$. Además, como subrayara GIMENO FELIU ${ }^{5}$, ignorar la versatilidad estratégica de la contratación pública supone renunciar al liderazgo institucional que corresponde a los poderes públicos.

Esta visión instrumental de la contratación pública implica la utilización de la contratación pública con el fin de orientar y afianzar comportamientos empresariales beneficiosos para el interés general, sin que necesariamente estén conectados con la directa satisfacción funcional del contrato ${ }^{6}$. De esta forma, se consideran objetivos secundarios o políticas horizontales, aquellos objetivos que no justifican la contratación, pero que conllevan aparejada una mejora con respecto a la situación preexistente ${ }^{7}$. Entre estos objetivos se

3 GIMENO FELIÚ, J. M. ${ }^{a}$ (2006): La nueva contratación pública europea y su incidencia en la legislación española. La necesaria adopción de una nueva Ley de contratos públicos y propuestas de reforma, Thomson-Civitas, Cizur Menor (Navarra), págs. 16 y 17. En relación con el empleo estratégico de la contratación pública es imprescindible la cita a GIMENO FELIU J. M. (2014): El nuevo paquete legislativo comunitario sobre contratación pública. De la burocracia a la estrategia. El contrato público como herramienta del liderazgo institucional de los poderes públicos, Aranzadi; PERNÁS GARCÍA J. (dir.) (2013): Contratación Pública Estratégica, Aranzadi; MEDINA ARNÁIZ T. (2011): "Comprando para asegurar nuestro futuro: la utilización de la contratación pública para la consecución de los objetivos políticos de la Unión Europea", en Gimeno Feliu (dir.), Observatorio de Contratos Públicos 2010, Aranzadi; GONZÁLEZ GARCÍA, V. (2015): "Sostenibilidad social y ambiental en la Directiva 2014/24/UE de contratación pública", Revista Española de Derecho Europeo.

${ }_{4}$ Vid. la reciente Comunicación de la Comisión Europea Conseguir que la contratación pública funcione en Europa y para Europa, 3-10-2017, COM (2017) 572 final, pág. 3.

5 GIMENO FELIÚ (2014).

Como destaca RODRIGUEZ ARANA [“La contratación del sector público como política pública”, en PÉRNAS GARCÍA (2013: 43)], las nuevas políticas públicas sugieren una llamada a la superación del falso dilema público-privado, y desde esta óptica, el contratista es también colaborador del sector público para la obtención de resultados sociales, de humanización de la realidad, de fortalecimiento de la dignidad del ser humano y de su entorno.

6 MEDINAARNÁIZ (2011: 45).

7 Sobre todo ello, vid. MEDINAARNÁlZ (2011: 45) y la bibliografía allí citada.

8 La contratación ecológica se define en la Comunicación de la Comisión Europea Contratación pública para un medio ambiente mejor como «un proceso por el cual las autoridades públicas tratan de adquirir mercancías, servicios y obras con un impacto medioambiental reducido durante su ciclo de vida, en comparación con el de otras mercancías, servicios y obras con la misma función primaria que se adquirirían en su lugar» [COM (2008) 400, página 4]. En relación con ésta, vid. RAZQUIN LIZARRAGA M. M. (dir.) (2017): Nueva contratación pública: mercado y medio ambiente, Aranzadi, y PERNAS GARCíA J. (2011), Contratación Pública Verde, La Ley.

9 Según el documento de la Comisión Europea. Guía para tomar en consideración cuestiones sociales en la contratación pública (2010) la compra socialmente responsable se refiere a las operaciones de contratación que «tienen en cuenta uno o más de los siguientes aspectos sociales: oportunidades de empleo, trabajo digno, cumplimiento con los derechos sociales y laborales, inclusión social (incluidas las personas con discapacidad), igualdad de oportunidades, diseño de accesibilidad para todos, consideración de los criterios de sostenibilidad, incluidas las cuestiones de comercio ético y un cumplimiento más amplio de la responsabilidad social de las empresas». Es este concepto amplio en el que se incluyen "compra pública social» y "compra ética». Como añade MEDINA ARNÁIZ T., [(2012): "La contratación pública socialmente responsable a través de la jurisprudencia del Tribunal de Justicia de la Unión Europea", REDA, 2012, pág. 218] la llamada "compra pública social» tiene por objeto integrar las inquietudes sociales en los procedimientos de adjudicación de un contrato público al tomar en consideración aspectos como la lucha contra el desempleo, la calidad en el empleo, la perspectiva de género, la contratación de personas con discapacidad o la reserva de contratos a Empresas de inserción y Centros Especiales de Empleo. Por su parte, la «compra ética» engloba otros supuestos en los cuales los elementos a valorar tienen más que ver con el cumplimiento de estándares éticos establecidos en las convenciones internacionales sobre condiciones laborales dignas, salarios mínimos y derechos de los trabajadores. Para un examen en profundidad de la posibilidad de integración de las cláusulas sociales en la contratación pública, GOSÁLBEZ PEQUEÑO, H. (2003): “¿Cláusulas sociales en la selección de los contratistas de las Administraciones públicas españolas?" Justicia Administrativa, núm. 20, págs. 27-67; MARTíNEZ PALLARÉS P. (2003): "Reflexiones sobre la inclusión de aspectos sociales y medioambientales como criterios de adjudicación de los contratos públicos", Contratación administrativa práctica, núm. 18; MOLINA NAVARRETE, C. (2008): "Relaciones laborales, política de empleo y compra pública socialmente responsable: las cláusulas sociales en la Ley 30/2007, de 30 de octubre, de Contratos del Sector Público", Revista de Trabajo y Seguridad Social, CEF, núm. 302, págs. 3-64: BERNAL BLAY, M. A. (2008): "Hacia una contratación pública socialmente responsable: Las oportunidades de la Ley 30/2007, de 30 de octubre, de Contratos del Sector Público", Revista Aragonesa de Administración Pública, núm. monográfico sobre el Derecho de los contratos del Sector Público, págs. 211-252, SAEZ LARA, C. (2009): "Las 
encuentra la compra ecológica ${ }^{8}$, la compra socialmente responsable ${ }^{9}$ y de forma algo más reciente, el estímulo a la innovación ${ }^{10}$.

Desde una perspectiva Europea, el debate sobre la visión instrumental de la contratación pública no es en absoluto novedoso. Ya en el célebre Libro Verde La Contratación pública en la Unión Europea: reflexiones para el futuro ${ }^{11}$ se afirmó que «la normativa de contratación pública puede contribuir a lograr los objetivos de las políticas social y medioambiental». No obstante, las dudas sobre la forma de conciliar dichos objetivos con el principio de libre concurrencia fueron recurrentes De este modo, la Directiva 2004/18/CE, de 31 de marzo de 2004, sobre coordinación de los procedimientos de adjudicación de los contratos públicos de obras, de suministro y de servicios, permitió desbrozar el camino al autorizar a los poderes adjudicadores a tener en cuenta aspectos ambientales y sociales en sus procedimientos de adjudicación de contratos, si bien se exigía su puesta en práctica compatibilizar dichos objetivos con los principios que presiden la contratación pública, esto es, los principios de concurrencia, transparencia, igualdad de trato y no discriminación ${ }^{12}$. Sin embargo, no se emplea ni una sola ocasión el término innovación, y ello aunque la integración formal de la contratación pública en la política más amplia de innovación se produce ya en $2003^{13}$. No obstante, hasta el año 2006 no se ha producido un esfuerzo para llevar esta integración a la práctica ${ }^{14}$, integración que obedece a un múltiple enfoque en el que se pretende estimular la innovación no sólo a través de la oferta -como ha sido tradicional-, sino a también través de la demanda.

Ahora bien, de forma más reciente el Derecho europeo no sólo se permite, sino que fomenta la utilización estratégica de la contratación pública y, en este rápido recorrido introductorio, la cita a la Estrategia Europa 2020 es insoslayable ${ }^{15}$. La Estrategia Europa 2020 afirma con rotundidad que «el año 2010 debe marcar un nuevo principio». Y en el marco de este nuevo comienzo la Comisión propone para la UE cinco objetivos cuantificables para 2020: el empleo, la investigación y la innovación, el cambio climático y la energía, la educación y la lucha contra la pobreza. Al servicio de la consecución de los mismos aparece reiteradamente la contratación pública.

En este contexto, no causa perplejidad que uno de los dos objetivos de la propuesta de Directiva del Parlamento europeo y del Consejo relativa a la contratación pública del año $2011^{16}$ consistiese en permitir que los compradores utilicen mejor la contratación pública en apoyo de objetivos sociales comunes como la protección del medio ambiente, una mayor eficiencia energética y en el uso de los recursos, la lucha contra el cambio climático, la promoción de la innovación, el empleo y la integración social y la prestación de servicios sociales de alta calidad en las mejores condiciones posibles ${ }^{17}$.

cláusulas sociales en los contratos del sector público", Relaciones Laborales, núm. 14, y MEDINAARNÁlZ, T. (2011): "Social Considerations in Spanish Public Procurement Law", Public Procurement Law Review, vol. 20 (2), págs. 56-79; RAMOS PÉREZ-OLIVARES A., La regulación de las cláusulas sociales en los contratos del sector público tras el RD Legislativo 2/2011, La Ley, 2012.

10 Sobre este concepto, vid. infra.

11 Comunicación adoptada por la Comisión el 27 de Noviembre de 1996, a propuesta del Señor MONTI, pág. 33.

12 MEDINA ARNAIZ (2010: 50). Nos remitimos a este trabajo para un análisis detallado de la progresiva incorporación de los objetivos secundarios a la contratación pública. En todo caso, como subraya la autora, la voluntad clara y decida por atender objetivos de interés general desde la regulación sobre contratos públicos llega en el año 2001 de la mano de dos Comunicaciones en las que la Comisión analiza las diversas opciones que ofrecía el marco jurídico comunitario entonces vigente para incorporar aspectos sociales y medioambientales en los contratos públicos. Se trata de la Comunicación sobre la legislación comunitaria de contratos públicos y las posibilidades de integrar aspectos medioambientales en la contratación pública [COM (2001) 274 final, de 4 de julio de 2001] y la Comunicación sobre la legislación comunitaria de contratos públicos y las posibilidades de integrar aspectos sociales en dichos contratos [COM (2001) 566 final de 15 de octubre de 2001].

${ }^{13}$ Vid. apartado 5.4 Comunicación de la Comisión Invertir en investigación: un plan de acción para Europa, COM (2003), 226 final/2, de 4 de junio de 2003.

14 Sobre la política de innovación y la contratación pública, vid. entre otros, EDLER J. y GEORGHIOU L. (2007): "Public procurement and innovation - Resurrecting the demand side", Research Policy, 36.

${ }^{15}$ Comunicación de la Comisión Europea EUROPA 2020 Una estrategia para un crecimiento inteligente, sostenible e integrador, Bruselas, 3-3-2010. COM (2010) 2020 final.

16 COM (2011) 896 final, 2011/0438 (COD). En relación con estas de propuestas de Directivas, vid. MORENO MOLINA J. A., "La cuarta generación de Directivas de la Unión Europea sobre contratos públicos", en Gimeno Feliu (dir.), Observatorio de Contratos Públicos 2012, Civitas, 2013 y GIMENO FELIU J. M., "Las nuevas Directivas -cuarta generación- en materia de contratación pública. Hacia una estrategia eficiente en compra pública", REDA, núm. 159, 2013.

17 Como se afirma en la propuesta de Directiva, esta se basa en un planteamiento de capacitación consistente en proporcionar a los poderes adjudicadores los instrumentos necesarios para contribuir a la realización de los objetivos estratégicos de Europa 2020 utilizando su poder adquisitivo para comprar bienes y servicios que promuevan la innovación, el respeto del medio ambiente y la lucha contra el cambio climático mejorando al mismo tiempo el empleo, la salud pública y las condiciones sociales. 
Estos objetivos se han plasmado en el considerando segundo de la finalmente aprobada Directiva 2014/24/UE, de 26 de febrero, sobre contratación pública y por la que se deroga la Directiva 2004/18/CE. Como se reconoce en dicho considerando,

«La contratación pública desempeña un papel clave en la Estrategia Europa 2020, establecida en la Comunicación de la Comisión de 3 de marzo de 2010 titulada "Europa 2020, una estrategia para un crecimiento inteligente, sostenible e integrador" ("Estrategia Europa 2020"), como uno de los instrumentos basados en el mercado que deben utilizarse para conseguir un crecimiento inteligente, sostenible e integrador, garantizando al mismo tiempo un uso más eficiente de los fondos públicos. Con ese fin, deben revisarse y modernizarse las normas vigentes sobre contratación pública adoptadas de conformidad con la Directiva 2004/17/CE del Parlamento Europeo y del Consejo, y la Directiva 2004/18/CE del Parlamento Europeo y del Consejo a fin de incrementar la eficiencia del gasto público, facilitando en particular la participación de las pequeñas y medianas empresas (PYME) en la contratación pública, y de permitir que los contratantes utilicen mejor la contratación pública en apoyo de objetivos sociales comunes.»

Y en este ámbito, la nueva Directiva incorpora múltiples herramientas al servicio de la promoción de la contratación ecológica, social y de innovación. Así, sin ánimo de exhaustividad, puede destacarse la regulación de las etiquetas ambientales y sociales, la flexibilización de la vinculación con el objeto del contrato de los criterios de adjudicación, la inclusión del ciclo de vida como criterio de adjudicación, el énfasis en la definición funcional del objeto del contrato, la introducción de una mayor flexibilidad en el empleo del procedimiento de licitación con negociación -que sustituye al negociado con publicidad-y del diálogo competitivo y el diseño de un nuevo procedimiento, la asociación para la innovación creado específicamente como herramienta para estimular ésta desde la demanda, etc.

La relevancia de esta nueva batería de herramientas dirigidas a la plasmación de una visión estratégica de la contratación pública no debe soslayarse, más aún cuando se constata que existe una voluntad real por parte de las instituciones europeas de que todos estos mecanismos tengan plena efectividad práctica. La reciente Comunicación de la Comisión Europea «Conseguir que la contratación pública funcione en Europa y para Europa» ${ }^{18}$ ha llamado la atención sobre el hecho de que los Estados miembros no están utilizando plenamente las posibilidades de la contratación pública como herramienta estratégica para fomentar objetivos de política social sostenibles y la innovación. En consecuencia, la Comisión anuncia nuevas iniciativas tendentes a garantizar una mayor aceptación de la contratación pública estratégica. Entre ellas, actualizar las orientaciones sobre la contratación ecológica y social ${ }^{19}$ y ofrecer orientaciones sobre la contratación de innovación.

En el plano del Derecho interno, la preocupación por la utilización estratégica de la contratación pública tampoco es reciente ${ }^{20}$, si bien, hasta la aprobación de las Directivas de 2014 la utilización de cláusulas sociales -no tanto ambientales, dado que su vinculación con el objeto del contrato resulta más aprehensible ${ }^{21}$ - se encontraba rodeada de una innegable halo de inseguridad jurídica. La azarosa vida del Decreto de la Comunidad de Madrid 213/1998, por el que se establecían medidas en la contratación administrativa de la Comunidad para apoyar la estabilidad y calidad del empleo, prueba suficientemente este extremo. Tras

18 Comunicación de 3-10-2017, COM (2017) 572 final, pág. 4.

19 Las orientaciones vigentes son las siguientes: Guía para tomar en consideración cuestiones sociales en la contratación pública. SEC (2010) 1258 final, de 19 de octubre de 2010, sólo existe una edición. Manual Adquisiciones Ecológicas, cuya tercera edición fue publicada en Abril de 2016.

${ }^{20}$ No obstante, también suscitaba dudas. Informe y Conclusiones de la Comisión de expertos para el estudio y diagnóstico de la situación de la contratación pública en España, Ministerio de Hacienda, Madrid, 2004, pág. 147.

Entre algunas de las primeras iniciativa, Plan de Contratación Pública Verde de la Administración General del Estado y sus Organismos Públicos, y las Entidades Gestoras de la Seguridad Social, aprobado por Orden 116/2008, de 21 de enero (BOE núm. 27, de 31 de enero de 2008), Guía para la Contratación Pública Responsable en Andalucía, Consejería de Medio Ambiente de la Junta de Andalucía, IDEAS (Iniciativas de Economía Alternativa y Solidaria), 2006 y, la Guía para la Compra Pública Ética y Sostenible de las Administraciones Públicas de Castilla-La Mancha, Red de Comercio Justo y Consumo Responsable de Castilla-La Mancha, 2007.

La integración de las políticas de innovación es mucho más cercana en el tiempo, si bien desde el año 2010 pueden señalarse una serie de hitos entre los que se encuentra la aprobación de la Estrategia Estatal de Innovación E2i (2 de julio de 2010), como parte de la Estrategia de Economía Sostenible aprobada en Diciembre de 2009 y la aprobación en 2011 de la Guía sobre Compra Pública Innovadora. Vid. VALCÁRCEL FERNÁNDEZ P. (2017): "La Compra Pública de Innovación (CPI). El procedimiento de adjudicación de Asociación para la Innovación" GAMERO CASADO/GALLEGO CÓRCOLES (dir.) Tratado de Contratos del Sector Público.

${ }^{21}$ En todo caso, también se plantean algunas cuestiones prácticas de interés. Vid. infra. 
una serie de sentencias contradictorias, el Decreto fue finalmente derogado ante las dudas que suscitaba su compatibilidad con el Derecho europeo ${ }^{22}$.

En la actualidad, son muchos los poderes públicos que han materializado esta visión estratégica de la contratación pública a través de instrumentos de diferente naturaleza ${ }^{23}$. Entre las causas que pueden explicar esta realidad pueden encontrarse razones muy diversas, que abarcan desde la aprobación de las Directivas sobre Contratación Pública de 2014 -mucho más posibilistas en este sentido-, la superación de los momentos más oscuros de la crisis económica hasta los cambios en la realidad política acaecidos en los últimos años. Y entre las políticas que se pretenden integrar con más decisión se encuentran las políticas sociolaborales, ámbito en que existe cierta dificultad dada las interpretaciones jurídicas divergentes que se están realizando del marco jurídico -integrado principalmente por el RD Legislativo 3/2011, de 14 de noviembre por el que se aprueba el Texto Refundido de la Ley de Contratos del Sector Público (en adelante TRLCSP)-, hoy vigente ${ }^{24}$.

\section{EL CARÁCTER INSTRUMENTAL DE LA CONTRATACIÓN PÚBLICA COMO ELEMENTO ESTRUCTURANTE DE LA LCSP. LA PRECEPTIVA INCORPORACIÓN DE CLÁUSULAS SOCIALES Y AMBIENTALES EN TODO PROCEDIMENTO DE LICITACIÓN}

Como se ha enfatizado, la Ley 9/2017, de 8 de noviembre, de Contratos del Sector Público, por la que se transponen al ordenamiento jurídico español las Directivas del Parlamento Europeo y del Consejo 2014/23/ UE y 2014/24/UE, de 26 de febrero de 2014 (en adelante LCSP) introduce cambios sustanciales, que van más allá de una mera actualización formal del TRLCSP para hacerlo así compatible con las Directivas Europeas del año $2014^{25}$. Y entre ellos ha de subrayarse que la visión estratégica se convierte en el principal eje de la contratación ${ }^{26}$. No sólo el preámbulo de la nueva norma alude a la «Estrategia Europea 2020», fija entre uno de los dos objetivos que inspiran la regulación contenida el de conseguir una mejor relación calidad-precio, especialmente mediante la inclusión de aspectos cualitativos, medioambientales sociales e innovadores vinculados al objeto del contrato e insiste en que la Ley pretende conseguir que se utilice la contratación pública como instrumento para implementar las políticas tanto europeas como nacionales en materia social, medioambiental, de innovación y desarrollo, de promoción de las pymes, sino que, lo que resulta todavía más importante, en el articulado de la nueva introduce la obligación de que esta visión estratégica impregne cada procedimiento de licitación. De esta forma, el artículo 1.3 LCSP establece que:

«En toda contratación pública se incorporarán de manera transversal y preceptiva criterios sociales y medioambientales siempre que guarde relación con el objeto del contrato, en la convicción de que su inclusión proporciona una mejor relación calidad-precio en la prestación contrac-

${ }^{22}$ Es preciso recordar que la Comisión Europea envió el Dictamen Motivado de 21 de diciembre de 2001 corregido por el de fecha 8 de febrero de 2002. Sobre estas cuestiones, vid. GALLEGO CÓRCOLES I. (2011): ¿¿Pueden incluirse cláusulas sociales en la contratación pública (I)?”, Contratación Administrativa Práctica, núm. 114.

${ }^{23}$ Sin ánimo de exhaustividad: Acuerdo de 20 de junio de 2017: "Código para una contratación pública socialmente responsable en el ámbito de la Administración de la Generalitat y el sector público que depende"; Instrucción 1/2016, relativa a la incorporación de cláusulas sociales en los contratos celebrados por el Ayuntamiento de Madrid, sus organismos autónomos y entidades del sector público municipal; Ley 3/2016, de 7 de abril, de Euskadi, para la inclusión de determinadas cláusulas sociales en la contratación pública; Acuerdo 44/2016, de 21 de julio, de la Junta de Castilla y León, por el que se aprueban directrices vinculantes para los órganos de contratación de la Administración General e Institucional de la Comunidad de Castilla y León sobre incorporación de aspectos sociales en la contratación. Al margen de todo ello, también son reseñables iniciativas privadas como el Foro de la Contratación Socialmente responsable (http://www.conr.es/).

${ }^{24}$ Como ya hemos advertido en GALLEGO CÓRCOLES. I (2017 a): "Las clausulas sociales como criterio de adjudicación", Contratación administrativa práctica, núm. 152 (en prensa) los Tribunales Administrativos de Recursos Contractuales han tenido ocasión de pronunciarse de forma reiterada sobre la admisibilidad de distintos criterios de adjudicación que contienen una dimensión social. Dada la complejidad de la materia y la ausencia de un criterio jurisprudencial claro es preciso destacar los intensos esfuerzos argumentativos que se realizan en la mayor parte de resoluciones. Del mismo modo, resulta innegable que no en todos los aspectos existe unidad de criterio, siendo en todo caso el TACRC el que está incorporando la visión más restrictiva. Por lo demás, tuve ocasión de analizar la jurisprudencia del TJUE, en cierto modo titubeante, en (2011), "Cláusulas sociales, contratación pública y jurisprudencia del TJUE", núm. 113, Contratación Administrativa Práctica.

25 Vid. GIMENO FELIU J. M. (2017 a), "La nueva regulación de la contratación pública en España desde la óptica de la incorporación de las exigencias europeas: hacia un modelo estratégico, eficiente y trasparente", en Gimeno Feliu (dir.), Estudio Sistemático de la LCSP, Aranzadi (en prensa).

${ }^{26}$ Ibidem. 
tual, así como una mayor y mejor eficiencia en la utilización de los fondos públicos. Igualmente se facilitará el acceso a la contratación pública de las pequeñas y medianas empresas, así como de las empresas de economía social»

Este precepto no formaba parte del proyecto de Ley. Sin embargo, fue aprobado por unanimidad por la Ponencia constituida en el Congreso de los Diputados. Mediante la adicción de este nuevo apartado al artículo 1 se persigue otorgar a estos objetivos estratégicos «no sólo la importancia debida sino la categoría jurídica necesaria que evite interpretaciones contrarias que todavía por desgracia se producen», de forma que se trata de «aclarar y explicitar [...] que los criterios sociales conforman un principio rector de la contratación pública y que su inclusión proporciona una mejor oferta de la prestación contractual, incluso desde el punto de vista económico» ${ }^{27}$. Dada la interpretación confusa que del nuevo marco del Derecho de la Unión Europea se estaba produciendo ${ }^{28}$, la inclusión de este precepto, en el que no está ausente cierto contenido didáctico ${ }^{29}$, parece a nuestro juicio totalmente pertinente. Es más, dada su ubicación sistemática -en el pórtico de la norma- plasma con cierta solemnidad la superación de un modelo economicista de contratación pública ${ }^{30}$

Por lo demás, tanto del art. 1.3 LCSP como del resto del articulado de la norma se puede desprender una cierta jerarquización de políticas públicas, de forma que se priorizan las relativas a políticas ambientales y sociales frente a la innovación. No obstante, esta afirmación puede no resultar totalmente precisa, dada la estrecha vinculación innovación e introducción de cláusulas sociales y ambientales en la contratación ${ }^{31}$.

El contenido prescriptivo del art. 1.3 LCSP no ha de ser desdeñado, ya que el mandato no sólo inequívoco, sino que se acompaña a lo largo de la norma de determinados mecanismos que permiten dotarlo de la necesaria efectividad. La visión estratégica de la contratación pública late en toda la norma. Así, en primer lugar, se reconocen una serie de cláusulas que tratan de asegurar el cumplimiento de obligaciones previas de tipo ambiental o social ${ }^{32}$. Igualmente ha de tenerse en cuenta la obligación de rechazar las ofertas incursas en presunción de temeridad cuando no se justifiquen en el cumplimiento de las obligaciones sociales, laborales o medioambientales -lo que incluye, y esta precisión no es en absoluto baladí, el incumplimiento de los convenios colectivos sectoriales vigentes (art. 149.4 LCSP ${ }^{33}$ ) - y la obligación de los órganos de contratación de tomar las medidas pertinentes para garantizar que en la ejecución de los contratos los contratitas cumplen las obligaciones aplicables en materia medioambiental social o laboral. En este sentido, el 201 LCSP previene que el incumplimiento de estas obligaciones, en especial, los incumplimientos o los retrasos

27 Vid. justificación de la enmienda 1041 del GP Vasco (EAJ-PNV) en el Congreso. En todo caso ha de tenerse en cuenta que la aceptación de dicha enmienda se efectúa con el añadido de «medioambientales», y «siempre que guarde relación con el objeto del contrato».

28 Nos remitimos a nuestro trabajo anterior GALLEGO CÓRCOLES (2017 a).

29 Así, en la Enmienda 1041 del GP Vasco (EAJ-PNV) en el Congreso también insiste en la necesidad de transmitir (a todas las Administraciones Públicas, a todos los órganos contratantes, así como a todas las personas responsables de la redacción de pliegos y de la licitación de contratos públicos), la idea fundamental de que la inclusión de criterios sociales y ambientales debe impregnar de forma transversal y obligatoria toda la contratación pública, configurando de este modo un sistema de corresponsabilidad social y de contratación pública responsable.

Se trata igualmente de explicitar que la inclusión de criterios sociales y ambientales no supone tan solo una cuestión ética o de justicia social, sino una potente y sinérgica herramienta de transformación que resulta altamente eficiente desde el punto de vista del interés público y de la propia eficiencia y racionalización de los presupuestos públicos destinados a contratación.

30 En todo caso, ha de advertirse que aunque el art. 1.3 LCSP hace referencia a «criterios» una interpretación sistemática de la norma aclara que no se refiere en exclusiva a criterios de adjudicación, sino al concepto más amplio de «cláusulas» ambientales y sociales, que no sólo engloban estos, sino también prescripciones técnicas, condiciones especiales de ejecución, etc.

31 Para comprobar dicha afirmación basta una mera lectura de la Guía para autoridades públicas sobre la Contratación Pública de Innovación, 2015; edited by: Procurement of Innovation Platform. ICLEI-Local Governments for Sustainability (Project coordinator). www.innovation-procurement.org. Así, entre los casos prácticos que relatan se encuentran «una solución concreta para reducir la contaminación atmosférica» o «innovación en limpieza: priorizar a las personas y al medio ambiente».

Sobre la idea de vinculación entre innovación y políticas ambientales y sociales insiste el estudio Strategic use of public procurement in promoting green, social and innovation policies realizado a instancias de la Comisión Europea, diciembre 2015.

32 Señala HERNÁEZ SALGUERO E. (2017): "Cláusulas sociales en la contratación pública", en Tratado de Contratos del Sector Público, Tirant Lo Blanch (en prensa), que este tipo de cláusulas no añadirían valor estratégico a la contratación pública.

33 De manera conexa, el art. 129 LCSP regula la información sobre las obligaciones relativas a la fiscalidad, protección del medio ambiente, empleo y condiciones laborales y de contratar a un porcentaje específico de personas con discapacidad. Si el órgano de contratación señalase en el pliego el organismo u organismos de los que los candidatos o licitadores pueden obtener la información pertinente, el órgano de contratación solicitará a los licitadores o a los candidatos en un procedimiento de adjudicación de contratos que manifiesten haber tenido en cuenta en la elaboración de sus ofertas las obligaciones derivadas de las disposiciones vigentes en materia de protección del empleo, condiciones de trabajo y prevención de riesgos laborales, y protección del medio ambiente. 
reiterados en el pago de los salarios o la aplicación de condiciones salariales inferiores a las derivadas de los convenios colectivos que sea grave y dolosa, dará lugar a la imposición de las penalidades. Por su parte, el apartado i) del artículo 211 de la LCSP establece entre las causas generales de resolución de los contratos «el impago, durante la ejecución del contrato, de los salarios por parte del contratista a los trabajadores que estuvieran participando en la misma, o el incumplimiento de las condiciones establecidas en los Convenios colectivos en vigor para estos trabajadores también durante la ejecución del contrato» ${ }^{34}$. Como es tradicional, determinadas prohibiciones de contratar están vinculadas con el cumplimiento de la legislación social, laboral y ambiental (vid. art. 71 LCSP).

Pues bien, al margen de estas cláusulas, se añaden otras cuya virtualidad es añadir un inequívoco valor estratégico a la contratación pública. Así, el art. 28.2 LCSP, cuando regula la necesidad e idoneidad del contrato, dispone que las entidades del sector público valorarán la incorporación de consideraciones sociales, medioambientales y de innovación como aspectos positivos en los procedimientos de contratación pública. Por su parte, el art. 35.1 LCSP impone que cuando se defina el objeto y tipo del contrato, se tenga en cuenta las consideraciones sociales, ambientales y de innovación ${ }^{35}$. Y en relación con este aspecto es preciso destacar que el art. 99 LCSP dispone que el objeto del contrato se podrá definir en atención a las necesidades o funcionalidades concretas que se pretenden satisfacer sin cerrar su objeto a una solución única, añadiendo el precepto que «en especial, se definirán de este modo en aquellos contratos en los que se estime que pueden incorporarse innovaciones tecnológicas, sociales o ambientales que mejoren la eficiencia y sostenibilidad de los bienes, obras o servicios que se contraten ${ }^{36}$.

De forma consecuente, determinadas consideraciones de tipo social y ambiental se incluyen en la regulación de la solvencia de los licitadores ${ }^{37}$. Por su parte, el art. 127 LCSP regula las etiquetas de tipo social o medioambiental -entre otras las relacionadas etiquetas de tipo social o medioambiental, como aquellas relacionadas con la agricultura o la ganadería ecológicas, el comercio justo, la igualdad de género o las que garantizan el cumplimiento de las Convenciones fundamentales de la Organización Internacional del Trabajo-. Resulta igualmente novedoso el contenido del art. 157.5 LCSP, que prevé la posibilidad de que la mesa de contratación solicite informes que permitan la verificación de las consideraciones sociales y ambientales ${ }^{38}$.

Finalmente, entre los mecanismos más potentes para dotar de efectividad al mandato de integración de las políticas sociales y ambientales en la contratación es preciso destacar no sólo la exhaustiva regulación de las cláusulas ambientales, sociales y ambientales como criterios de adjudicación, sino también la preceptiva utilización de condiciones de ejecución relacionadas con estas políticas sectoriales ${ }^{39}$.

Un estudio exhaustivo de todos estos mecanismos desbordaría el objeto de este trabajo. Por ello nos limitaremos a analizar aquellos ámbitos en los que, a mi juicio, la intensidad de la reforma en aras a conseguir

${ }^{34}$ Esta causa de resolución se recoge igualmente en los contratos de los poderes adjudicadores que no tengan la condición de Administraciones Públicas. Vid. art. 319.2 LCSP.

${ }_{35}$ No debe soslayarse la importancia del momento de determinación del objeto contrato de cara a la consecución de objetivos estratégicos. Vid. por ejemplo IJCC Aragón 16/2015, de 4 de noviembre, que señala que la primera ocasión de integrar aspectos sociales en un contrato público se presenta en el momento de elección del objeto del contrato, o en la fijación de sus especificaciones técnicas.

36 Como explica la Guía 2.0 para la Compra Pública de Innovación (2015) elaborada por el hoy Ministerio de Economía, Industria y de Competitividad, las especificaciones técnicas formuladas en términos de rendimiento o de exigencias funcionales se definen como aquéllas que describen la función, objetivo o rendimiento que se pretende alcanzar, en vez de especificar el producto o servicio que es objeto del contrato. En otras palabras, las especificaciones funcionales se centran en las necesidades reales que el contrato busca satisfacer y dejan que el mercado sugiera el mejor camino para su consecución, sin establecer elementos técnicos obligatorios. Un ejemplo de especificación de este tipo sería la siguiente, lluminación de vías urbanas con sistemas de iluminación capaces de reducir hasta el $70 \%$ de consumo eléctrico manteniendo un poder lumínico equivalente a sistemas AAA (pág. 48 y ss.).

${ }^{37}$ En relación con la acreditación del cumplimiento de las normas de gestión medioambiental, vid. arts. 881.d) y 90.1f) LCSP en relación con el 94 LCSP. Mayor novedad revisten aspectos relacionados con la solvencia social. Así, en el ámbito de contrato de suministros, el art. $89.1 \mathrm{~g}$ ) establece como forma de acreditación de la solvencia la «indicación de los sistemas de gestión de la cadena de suministros incluidos los que garanticen el cumplimiento de las Convenciones fundamentales de la Organización Internacional del Trabajo, y de seguimiento que el empresario podrá aplicar al ejecutar el contrato». Según el art. 90.3 LCSP, si el objeto contractual requiriese aptitudes específicas en materia social, de prestación de servicios de proximidad y otras análogas, en todo caso se exigirá como requisito de solvencia técnica o profesional la concreta experiencia, conocimientos y medios en las referidas materias. Finalmente, el art. 93 LCSP, al hacer referencia a la acreditación del cumplimiento de las normas de garantía de la calidad, alude expresamente entre estas las relativas a la «accesibilidad para las personas con discapacidad».

${ }^{38}$ En concreto, dispone el precepto se podrán requerir informes las organizaciones sociales de usuarios destinatarios de la prestación, a las organizaciones representativas del ámbito de actividad al que corresponda el objeto el contrato, a las organizaciones sindicales, a las organizaciones que defiendan la igualdad de género y otras organizaciones para la verificación de las consideraciones sociales y ambientales.

39 Especialmente, art. 202 LCSP, vid. infra. 
una integración efectiva de objetivos políticos en la contratación pública es mayor: criterios de adjudicación, condiciones de ejecución y mecanismos procedimentales.

\section{LA UTILIZACIÓN DE CLÁUSULAS AMBIENTALES, SOCIALES Y DE INNOVACIÓN COMO CRITERIOS DE ADJUDICACIÓN}

\subsection{Hacia la superación de los obstáculos impuestos tradicionalmente por el Derecho de la Unión Europea: la relajación de la exigencia de vinculación con el objeto del contrato}

Uno de los requisitos que ha de cumplir cualquier criterio de adjudicación para resultar válido es su vinculación con el objeto del contrato. Se trata de una condición que de origen jurisprudencial, se incorpora en el art. 53.1 a) de la Directiva 2004/18/CE ${ }^{40}$. En un interpretación estricta, este requisito supone un importante límite a la introducción de criterios de adjudicación que obedezcan a objetivos secundarios en la contratación pública. Porque si bien, como demuestra de la STJUE de 17 de septiembre de 2002, As. C-513/99, Concordia Bus Finland ${ }^{41}$, la vinculación material de un criterio de tipo ambiental con el objeto del contrato no puede a priori resultar excesivamente difícil ${ }^{42}$, mayores dudas suscita este tipo de vinculación cuando de un criterio social se trata. Dudas que no aclaró la primera jurisprudencia del TJUE, pues los pronunciamientos STJUE de 20 de septiembre de 1988, Asunto C-31/87, Gebroeders Beentjes. y STJUE de 26 de septiembre de 2000, C-225/98, ambos relativos a la posibilidad de valorar en la fase de adjudicación la creación de empleo, fueron ciertamente contradictorios ${ }^{43}$.

Es sabido que la Comisión Europea fue en un principio reacia a admitir cláusulas sociales como criterios de adjudicación ${ }^{44}$. Por ello, en la Guía de 2010 sobre incorporación de cuestiones sociales en la contratación pública ${ }^{45}$, realiza un importante esfuerzo para explicar qué criterios de adjudicación de carácter social guardan una relación directa con el objeto del contrato. Y se facilitan ejemplos de cláusulas admisibles y cláusulas que no lo son. Respetaría así el Derecho de la Unión que en una contratación pública para la atención de personas con discapacidad, los criterios de adjudicación pueden tener encuentra requisitos relativos a satisfacer las necesidades específicas de cada categoría de usuario (por ejemplo, personalización del servicio según la edad, el sexo o las dificultades sociales de los usuarios, etc.). Sin embargo, no sería posible utilizar criterios de adjudicación relacionados con la creación de nuevos puestos de trabajo en el mercado local, pues un criterio de ese tipo no está vinculado al objeto del contrato (por ejemplo, la construcción de una obra $)^{46}$.

40 Más en extenso, ARROWSMITH S. (2014): The Law of Public and Utilities Procurement, Sweet and MaxWell, Tercera Edición, págs. 531.

${ }^{41}$ En dicha sentencia, el Tribunal concluyó que los criterios relativos al nivel de las emisiones de óxidos de nitrógeno y al nivel de ruido de los autobuses deben considerarse relacionados con el objeto de un contrato relativo a la prestación de servicios de transporte urbano en autobús.

42 En todo caso, dichas dificultades pueden existir, como demuestra la Resolución del TACPJ Andalucía 410/2015 relativa a un «Servicio de gestión de residuos», en el que se puntuaba la existencia de una planta de tratamiento de residuos en la Comunidad Autónoma de Andalucía, lo que se justificaba con el argumento de que tenía por finalidad minimizar el riesgo medioambiental y sanitario. El Tribunal concluyó que el criterio de «la distancia entre los centros y la planta de tratamiento es una cuestión puramente accidental, lo que impide considerarla como directamente vinculada al objeto del contrato» y por tanto infringe los principios de igualdad de trato y no discriminación y de libre concurrencia. Por su parte, la Resolución del TACRC 407/2017 analiza la exigencia de la inscripción en el Registro de la huella de carbono impuesta por los Pliegos para la conservación y mantenimiento de los jardines de un municipio, que considera que no ene directa relación con el objeto del contrato, y además es contraria al principio de igualdad.

Sobre la utilización de criterios de adjudicación de carácter ambiental vid. en la obra colectiva RAZQUIN LIZARRAGA M. M. (2017): Nueva contratación pública: mercado y medio ambiente, Aranzadi, los siguientes trabajos FERNÁNDEZ ACEVEDO R.: "Los retos ambientales de las nuevas Directivas. La contratación pública como herramienta" (pág. 114 y ss.); RAZQUIN LIZARRAGA M. M.: "Mecanismos para la inclusión de cláusulas ambientales en los contratos públicos" (pág. 147 y ss.); ALENZA GARCÍA J. F., "Contratación pública y residuos" (pág. 230 y ss.) y MIRANZO DÍAZ J.: "Los criterios de adjudicación ambientales en las Directivas de 2014".

${ }^{43}$ Según la primera de dichas sentencias, la cláusula «condiciones de emplear a trabajadores en paro prolongado» no guarda relación con los criterios de adjudicación del contrato a que alude el artículo 29 de la Directiva. Según la segunda, el «criterio de adjudicación adicional relacionado con la lucha contra el desempleo» es compatible con el Derecho Europeo. Para un análisis más exhaustivo, me remito a mi anterior trabajo GALLEGO CORCOLES (2011).

44 Vid. Comunicación interpretativa sobre la legislación comunitaria de contratos públicos y las posibilidades de integrar aspectos sociales en dichos contratos, COM (2001) 566 final.

45 Citada, pág. 37.

${ }^{46}$ Cfr. con la doctrina establecida en la STJUE de 26 de septiembre de 2000, C-225/98, 
De esta forma, la Comisión abogaba por una interpretación estricta de la vinculación del criterio con el objeto del contrato que resulta definitivamente superada tras la relevante STJUE de 10 de mayo de 2012 , Comisión c. Países Bajos, as. C-368/1047. Esta sentencia analiza la compatibilidad con el Derecho de la Unión de la exigencia de una etiqueta ecológica (EKO) y de una etiqueta relativa al comercio justo (MAX HAVELAAR) en el marco del procedimiento de adjudicación de un contrato de suministro de té y café. La sentencia reviste particular interés porque analiza si estas etiquetas eran admisibles tanto como especificación técnica, criterio de adjudicación y como requisito de capacidad técnica.

En lo que a los criterios de adjudicación respecta, la sentencia introduce una interpretación del Derecho de la contratación pública europeo que supera las concepciones más estrictas de la vinculación de los criterios de adjudicación al objeto del contrato. Porque, se admite que los poderes adjudicadores pueden elegir criterios de adjudicación basados en consideraciones de carácter social sin que tengan que referirse necesariamente a los usuarios de las obras, suministros y servicios objeto del contrato. De esta forma, se entiende que una etiqueta relativa al comercio justo presenta una vinculación suficiente con el objeto del contrato controvertido. Ello es así porque:

« [...] con arreglo a la descripción del contrato [...], ese contrato tenía por objeto, [...] el suministro del café, el té y otros ingredientes necesarios para la elaboración de las bebidas disponibles en las máquinas expendedoras. Además, de la redacción del criterio de adjudicación controvertido resulta que éste sólo se refería a los ingredientes que se suministraran en el marco de dicho contrato, sin ninguna implicación con respecto a la política general de compras de los licitadores. Por consiguiente, esos criterios se referían a productos cuyo suministro constituía una parte del objeto de dicho contrato.

Por último, como se desprende del punto 110 de las conclusiones de la Abogado General, no es necesario que un criterio de adjudicación se refiera a una característica intrínseca de un producto, es decir, a un elemento incorporado materialmente en éste. [...]».

Pues bien, entre las novedades de Directiva 2014/24/UE se encuentra el hecho de que las características sociales y también las relativas a la innovación se contemplan de forma expresa en el articulado como aspectos que pueden incluir los criterios de adjudicación (art. 67.1). Sin embargo, quizá el elemento más destacable en la nueva regulación no es esta mención expresa, si no que aunque se sigue exigiendo que el criterio de adjudicación esté vinculado al objeto del contrato, este requisito se flexibiliza, de forma que esta vinculación no implica que el elemento objeto de valoración se incorpore físicamente a la prestación. Se codifica así la doctrina de la sentencia Comisión contra Países Bajos antes citada.

De esta forma, el art. 67.3 de la Directiva establece que «se considerará que los criterios de adjudicación están vinculados al objeto del contrato público cuando se refieran a las obras, suministros o servicios que deban facilitarse en virtud de dicho contrato, en cualquiera de sus aspectos y en cualquier etapa de su ciclo de vida, incluidos los factores que intervienen: a) en el proceso específico de producción, prestación o comercialización de las obras, suministros o servicios; b) en un proceso específico de otra etapa de su ciclo de ida, incluso cuando dichos factores no formen parte de su sustancia material».

Las dificultades han surgido a la hora de determinar en qué consiste un «proceso específico de producción y prestación». Y las dudas se han planteado porque no existe referencia a las condiciones laborales de los trabajadores empleados en la ejecución del contrato como criterio de adjudicación en el art. 67.3 de la Directiva. Dicho en otros términos, de los considerandos de la Directiva se desprende que puede favorecerse la contratación de sectores desfavorecidos de la población. Ahora bien, no se aclara expresamente si a través de ésta, pueden mejorarse las condiciones laborales de los trabajadores que van a realizar la prestación.

La cuestión no es meramente retórica ni ajena a nuestra realidad práctica. De hecho, la admisibilidad de criterios tendentes a garantizar determinadas condiciones laborales a los trabajadores destinados a la ejecución del contrato es uno de los supuestos en los que se ha producido una mayor disparidad de criterio entre, por un lado, determinados Tribunales Administrativos Autonómicos de Recursos Contractuales -especialmente el TACP Madrid y el TACP Aragón-y, por otro, el TACRC. Por ejemplo, mientras que un criterio de adjudicación tendente a valorar la existencia de un plan de conciliación social ha sido admitido por la RTACP Madrid de 3 de febrero de 2016 y por el ATAPC de Aragón de 30 de agosto de 2016, un criterio similar ha

${ }^{47}$ En relación con esta sentencia, vid. MEDINAARNÁIZ T., "Comercio justo y contratación pública”, en PERNÁS GARCíA J. (dir.), Contratación Pública Estratégica, Aranzadi, 2013, págs. 267. 
sido anulado por la TACRC de 27 de julio de 2017, ya que dicha resolución considera que la conciliación no se conecta con el objeto del contrato. Especialmente controvertido ha resultado el criterio de adjudicación relativo al compromiso de aplicación del convenio estatal sectorial durante toda la vigencia del contrato. Criterio que viene siendo admitido por el Tribunal Administrativo de Contratación Pública de la Comunidad de Madrid ${ }^{48}$, aunque haya sido anulado por la STSJ Madrid de 7 de junio de 2017. Por su parte, el TACRC también ha negado que pueda aplicarse el compromiso de aplicación del convenio estatal como criterio de adjudicación entre otras, en la Resolución de 16 de diciembre de $2016^{49}$.

\subsection{La regulación de los criterios de adjudicación de carácter estratégico en la LCSP}

La nueva LCSP transpone las determinaciones relativas a la inclusión de criterios de adjudicación de carácter ambiental, social y de innovación en sus artículos 145.2 y 145.6 LCSP, precepto éste que fue aprobado por unanimidad en la Ponencia constituida en el Congreso ${ }^{50}$.

El art. 145.2 LCSP dispone que los criterios cualitativos que establezca el órgano de contratación para evaluar la mejor relación calidad-precio podrán incluir aspectos medioambientales o sociales, vinculados al objeto del contrato, y podrán ser, entre otros, «la calidad, incluido el valor técnico, las características estéticas y funcionales, la accesibilidad, el diseño universal o diseño para todas las personas usuarias, las características sociales, medioambientales e innovadoras, y la comercialización y sus condiciones» ${ }^{51}$. Por otro, la ausencia de exigencia de vinculación intrínseca con el objeto del contrato se regula en el apartado sexto del art. 145 LCSP, coincidente con el art. 67 de la Directiva, si bien se añade en la norma española una especial referencia a «formas de producción, prestación y comercialización medioambiental socialmente sostenibles y justas».

A diferencia de la Directiva, no obstante, la nueva Ley añade en el art. 145.6 LCSP, sin carácter exhaustivo, un elenco de características ambientales y sociales a las que podrán referirse los criterios de adjudicación.

Así, las características medioambientales podrán referirse, entre otras, a la reducción del nivel de emisión de gases de efecto invernadero; al empleo de medidas de ahorro y eficiencia energética y a la utilización de energía procedentes de fuentes renovables durante la ejecución del contrato; $y$ al mantenimiento o mejora de los recursos naturales que puedan verse afectados por la ejecución del contrato.

Por su parte, las características sociales del contrato se referirán, entre otras, a las siguientes finalidades: al fomento de la integración social de personas con discapacidad, personas desfavorecidas o miembros de grupos vulnerables entre las personas asignadas a la ejecución del contrato y, en general, la inserción sociolaboral de personas con discapacidad o en situación o riesgo de exclusión social; la subcontratación con Centros Especiales de Empleo o Empresas de Inserción; los planes de igualdad de género que se apliquen en la ejecución del contrato y, en general, la igualdad entre mujeres y hombres; el fomento de la contratación femenina; la conciliación de la vida laboral, personal y familiar; la mejora de las condiciones laborales y salariales; la estabilidad en el empleo; la contratación de un mayor número de personas para la ejecución del contrato; la formación y la protección de la salud y la seguridad en el trabajo; la aplicación de criterios éticos y de responsabilidad social a la prestación contractual; o los criterios referidos al suministro o a la utilización de productos basados en un comercio equitativo durante la ejecución del contrato.

48 ATACP Madrid 3 de febrero de 2016, Madrid 6 de octubre de 2016, de 18 de enero de 2017 y 1 de febrero de 2017 . ATACP Madrid de 19 de julio de 2017. En cuanto a los pronunciamientos judiciales citados por la recurrente y que avalarían su tesis, concretamente la Sentencia de 7 de junio de 2017, de la Sección Tercera, de la Sala de lo Contencioso Administrativo del Tribunal Superior de Justicia de Madrid, este Tribunal no desconoce su existencia pero cabe citar igualmente la Sentencia de 30 de mayo de 2003 , de la Sección Novena de esa misma Sala y Tribunal, que se pronunció a favor del Decreto 213/98, de 17 de noviembre, del Consejo de Gobierno de la Comunidad de Madrid, que establecía medidas en la contratación administrativa de la Comunidad, para apoyar la estabilidad y calidad del empleo, en definitiva criterios objetivos de adjudicación de los contratos, en relación con la estabilidad en el empleo y la contratación de trabajadores minusválidos por encima del mínimo legal. [...]”.

49 En detalle, GALLEGO CÓRCOLES I. (2017 a).

50 El texto definitivamente aprobado es consecuencia de la aceptación de las enmiendas 366 del GP Ciudadanos, 1066 del GP Vasco (EAJ-PNV), 616, 619 y 800 del GP Socialista y de la enmienda transaccional procedente de las enmiendas 70,96 , 99 y 118 del GP Confederal de Unidos Podemos-En Comú Podem-En Marea, 365 y 367 del GP Ciudadanos y 1064, 1065, 1067 del GP Vasco (EAJPNV), 435, 617, 621, 625 y 626 del GP Socialista.

51 Cierto es que, a diferencia del art. 53 Directiva 2004/18/CE, el art. 150.1 TRLCSP hacía referencia a criterios sociales de adjudicación en el articulado, al aludir a la «satisfacción de exigencias sociales que respondan a necesidades, definidas en las especificaciones del contrato, propias de las categorías de población especialmente desfavorecidas a las que pertenezcan los usuarios o beneficiarios de las prestaciones a contratar». Se correspondía con el considerando 46 de dicha directiva y mostraba una mayor sensibilidad del legislador español hacia la introducción de criterios sociales. 
Dadas las dudas aplicativas que hemos resaltado, la introducción de un elenco no exhaustivo -pero sí amplio- de criterios de adjudicación admisibles resultaba insoslayable para garantizar un mínimo de seguridad jurídica. En este sentido, interesa destacar que, confirmando la línea interpretativa del TACP Madrid, la mejora en las condiciones laborales de los trabajadores puede ser tomada en consideración como criterio de adjudicación. Y a mi juicio, es esta además la interpretación más pausible desde la perspectiva del Derecho de la Unión Europea. Como ha señalado ARROWSMITH ${ }^{52}$, la clara simetría establecida entre criterios de adjudicación y condiciones de ejecución que establece la Directiva 2014/24/UE muestra la admisibilidad de este tipo de consideraciones sociales como criterios de adjudicación, siempre y cuando se refieren a la ejecución de la concreta prestación y no de otro tipo de actividades del operador económico. De esta forma, como señala la autora que seguimos en este punto, este tipo de criterios vinculados a las condiciones laborales estarían bien incluidos en el concepto de «prestación», bien habría que entender que el listado del art. 67.3 no es exhaustivo, tal y como por otro lado, se desprende tanto del tenor literal de dicho artículo como del considerando $92^{53}$.

Por lo demás, en el largo elenco 145.6 LCSP se incluyen algunos criterios que ya habían sido objeto de controversia. Por ejemplo, se aclara que los criterios pueden referirse al fomento de la integración social de personas desfavorecidas o miembros de grupos vulnerables entre las personas asignadas a la ejecución del contrato ${ }^{54}$. Del mismo modo, se confirma la validez de criterios de adjudicación relativos a la la subcontratación con Centros Especiales de Empleo o Empresas de Inserción ${ }^{55}$ y a la estabilidad en el empleo ${ }^{56}$. También se aclara que los criterios de adjudicación pueden valorar la existencia de planes de conciliación, cuestión que había sido objeto de resoluciones contraditorias ${ }^{57}$. Especial relevancia tiene la alusión a «la mejora de las condiciones laborales y salariales», que permite disipar las dudas susictadas entorno a la posibilidad de valorar los compromisos de mantenimiento de las condiciones salariales fijados en convenios colectivos de carácter sectorial, admisibles siempre que se respete el Derecho social europeo, en los términos que señalaremos más adelante.

Finalmente, la Ley no establece ejemplo alguno de criterios de adjudicación que valoren la innovación. Como ejemplos de este tipo de criterios se pueden citar: mayor ahorro energético futuro derivado de la solución de innovación; mejora en el medioambiente (uso de materias primas, uso de agua, emisiones, residuos, reciclabilidad, etc.) como consecuencia directa de la solución de innovación; propuestas de desarrollo de actividades de I+D en colaboración con otros operadores económicos, como Universidades y Centros Tecnológicos ${ }^{58}$. Como puede advertirse, en más de una ocasión este tipo de criterios estarán estrechamente vinculado con otras políticas sectoriales.

\subsection{Los límites a la introducción de consideraciones estratégicas como criterios de adjudicación}

El art. 145.5 LCSP establece los requisitos que debe cumplir todo criterio de adjudicación, tenga carácter estratégico o no. Pues bien, al margen de dichos condicionantes, los límites que en la práctica suscita de manera recurrente la utilización de criterios sociales y ambientales son los siguientes: vinculación con el objeto

52 ARROWSMITH S.(2014): The Law of Public and Utilities Procurement, Sweet and MaxWell, Tercera Edición, 2014, págs. 746. Enfatiza igualmente el carácter simétrico de la regulación BORDALO FAUSTINO P. (2014): "Award Criteria in the New EU Directive on Public Procurement", PPLR, núm. 23, págs. 130-131.

El paralelismo entre criterios de adjudicación y condiciones de ejecución, en todo caso, está igualmente claramente establecido en los considerando 93, 97 y 99.

${ }^{53}$ En efecto, en dicho considerando se alude expresamente a que «en el contexto de la mejor relación calidad-precio, la presente Directiva incluye una lista no exhaustiva de posibles criterios de adjudicación que incluyen aspectos sociales y mediambientales».

${ }^{54}$ La validez de un criterio de este tipo fue negada por RTACRC de 27 de julio de 2017, que no encontró el nexo de unión suficiente con el objeto del contrato. Por su parte, el ATCP Navarra de 8 de agosto de 2016 consideró ilegal un criterio de adjudicación que valora la presencia de mujeres en el equipo técnico que va a desarrollar el trabajo. Sobre la posibilidad de incorporar criterios de adjudicación vinculados a la igualdad de género, vid. VALCÁRCEL FERNÁNDEZ P., "Promoción de la igualdad de género a través de la contratación pública" en la obra colectiva ya citada Contratación Pública Estratégica, págs. 329 a 368.

55 La validez de un criterio tal fue admitida por la RTACP Madrid de 10 de mayo de 2017 y por ATAPC Aragón de 30 de agosto de 2016 (rec. 72/2016). No es admisible sin embargo para la TACRC 27 de julio de 2017.

56 Sobre la validez de un criterio de adjudicación que toma en consideración la conversión de todos los contratos temporales de todas las personas trabajadoras afectas a la prestación del servicio en indefinidos o compromiso de mantener la totalidad de los contratos como indefinidos durante toda la ejecución del contrato, si todos los contratos suscritos por la entidad licitadora ya son indefinidos, vid. RTACP Madrid de 6 de octubre de 2016.

${ }^{57}$ La admisión de un criterio de adjudicación tendente a valorar la existencia de un plan de conciliación social resulta más controvertida. Ha sido admitida por el ATACP Madrid 3 de febrero de 2016.

58 Vid. la citada Guía 2.0 para la Compra Pública de Innovación (2015) pág. 58. 
del contrato, respeto a las políticas empresariales, repercusión en la calidad de la prestación y salvaguardia del principio de proporcionalidad. Al examen de estos cuatro límites dedicaremos las siguientes líneas.

La incorporación de una cláusula de tipo estratégico como criterio adjudicación exige una la vinculación de ésta -no necesariamente material- con el objeto del contrato. De esta forma, las políticas de responsabilidad medioambiental o social de la empresa no pueden ser objeto de valoración en la fase de adjudicación ${ }^{59}$.

Desde el punto de vista de la necesaria vinculación con el objeto del contrato de un criterio ambiental es ineludible la cita a la STJUE de 4 de diciembre de 2003, Wienstrom, as. C-448/01), en la que se declaró que el concreto criterio de adjudicación analizado relativo al suministro de energía verde no se refiere a la prestación que es objeto del contrato, sino a cantidades que los licitadores suministraron o van a suministrar a otros clientes distinto de la entidad adjudicadora. Por ello, no se considera válido (apartado 67).

En relación con la necesaria exigencia de vinculación con el objeto del contrato, la RTACRC 24 de abril de 2015 (rec. 265/2015) anula un criterio de adjudicación consistente en la declaración de puestos de trabajo, ya que no se adivina cúal es la relación con el objeto de la prestación del volumen de la plantilla del licitador. Por la misma razón, RTARCJ Andalucía de 18 de febrero de 2016 (rec. 46/2016) declara nulo el criterio "Compromiso con el desarrollo de la economía social»" ${ }^{60}$. Finalmente, la RTACRC de 5 de mayo de 2017 (rec. 408/2017) ha anulado un criterio de adjudicación que consistía en otorgar 0,5 puntos a aquellos licitadores que acreditasen ser firmantes del Pacto Mundial de Naciones Unidas.

Otro límite que se ha reiterado es la prohibición de introducción de aquellas cláusulas que supongan una injerencia indebida en la política empresarial de la empresa ${ }^{61}$, criterio, en todo caso, que encierra la aplicación de un concepto que se nos antoja ciertamente indeterminado, ya que estas medidas precisamente pretenden influir en las políticas empresariales. No obstante, como expresivo ejemplo de la virtualidad de este límite puede citarse la doctrina ya consolidada que considera inválido el criterio de adjudicación relativo al compromiso de subrogación de los trabajadores de la contratista saliente, criterio que se reputa resultaría contrario a lo establecido en la legislación laboral y en los convenios colectivos ${ }^{62}$.

Por lo demás, un tercer elemento que con frecuencia se exige para la inclusión de los criterios estratégicos es su repercusión en la calidad de la prestación. Pero a mi juicio, en aquellos supuestos en los que con mayor frecuencia surge este debate -una vez más, en relación con la inclusión de criterios sociales- la utilización de este requisito como límite puede empañar el debate. Y es que en más de una ocasión la vinculación del criterio social con el incremento directo en la calidad de la prestación es más que forzada ${ }^{63}$. El criterio estratégico no siempre repercutirá con la misma intensidad en la mejora funcional de la concreta prestación. Lo que deben añadir este tipo de criterios siempre es una mayor calidad en la contratación, entendida en términos amplios. En este punto, es difícil expresar la vinculación entre criterio estratégico y la calidad de la contratación de una forma más sugerente a la reflejada en las conclusiones de la Abogado General Kokott ${ }^{64}$ en el asunto c-368/10, que, como se recordará se refería a un supuesto de valoración de la etiqueta de comercio justo. Según estas conclusiones, «aunque el sabor del azúcar, en sentido estricto, no es diferente en función de si ha sido adquirido de forma justa o injusta, un producto que ha llegado al mercado en condiciones injustas deja un regusto más amargo en el paladar de los clientes conscientes de la responsabilidad social».

Finalmente, en determinados Acuerdos de los Tribunales Administrativos de Recursos Contractuales, la admisibilidad de la cláusula social se vincula al respecto al principio de proporcionalidad, que se traduce en la exigencia de que el criterio en cuestión no tenga un valor ponderado excesivamente amplio ${ }^{65}$. Se

59 Así, el considerando 97 afirma que: «la condición de que exista un vínculo con el objeto del contrato excluye los criterios y condiciones relativos a la política general de responsabilidad corporativa, lo cual no puede considerarse como un factor que caracterice el proceso específico de producción o prestación de las obras, suministros o servicios adquiridos. En consecuencia, los poderes adjudicadores no pueden estar autorizados a exigir a los licitadores que tengan establecida una determinada política de responsabilidad social o medioambiental de la empresa».

60 Este criterio se contenía dos subcriterios: Entidades o empresas participadas mayoritariamente por sus trabajadores: 10 puntos. Entidades o empresas donde las diferencias salariales no superen 2 veces el mayor salario sobre el menor salario: 10 puntos.

61 Vid. por ejemplo ATAPC Aragón de 30 de agosto de 2016.

62 Vid. STSJ Madrid 23 de febrero de 2011, SSTS de 25 de enero de 2013 y de 23 de enero de 2017. Vid. igualmente RTACP Madrid de 14 de julio de y RTACRC de 1 junio de 2017.

63 A mi juicio, precisamente la exigencia de una vinculación directa entre el criterio estratégico y la calidad de la prestación es el origen de la doctrina sobre la admisibilidad de los criterios sociales que de forma tan restrictiva está elaborando el TARC. Vid. GALLEGO CÓRCOLES (2017 a).

64 Conclusiones presentadas el 15 de diciembre de 2011.

65 Resolución del TACRC 21 de abril de 2017 para la que «dentro del valor de los subjetivos, la reserva de 20 puntos para la calidad en el empleo resulta notablemente superior al otro, el plan de trabajo para la prestación del servicio y supone también un por- 
trata en todo caso de un condicionante que no se exige de forma unánime por los Tribunales de Recursos Contractuales ${ }^{66}$. La necesidad de que los criterios de adjudicación respeten el principio de proporcionalidad se recoge ahora de forma expresa en el art. 145.5 c) LCSP. Y más allá de predeterminar una determinado porcentaje del criterio estratégico en cuestión, a mi juicio el respeto a este principio en cada procedimiento de licitación concreto dependerá tanto de su específica configuración como de la naturaleza de la prestación objeto de la contratación. Como se ha señalado ${ }^{67}$, para evitar que un criterio resulte excesivo o proporcionado, los beneficios que se derivan de un criterio de adjudicación, en cuanto que éste permite identificar una oferta ventajosa para los intereses públicos, deben superar a los perjuicios que el mismo supone para la libertad empresarial. Dicho en los términos de la jurisprudencia europea, el criterio estratégico no debe producir una «distorsión injustificada» ${ }^{68}$.

Así, por ejemplo, se ha destacado que no existe un máximo fijado para la ponderación que debe asignarse a los criterios de adjudicación de carácter medioambiental. Sin embargo, habrá que tener en cuenta la no duplicación de ninguna evaluación que ya se haya realizado en la fase de selección ${ }^{69}$. En este sentido, Comisión Europea recomienda que deba considerarse: a) cuán importantes son los objetivos medioambientales para el contrato, en comparación con otras consideraciones como el coste y la calidad general; b) la medida en que estas consideraciones se abordan mejor en los criterios de adjudicación, como complemento o en lugar de especificaciones, criterios de selección y cláusulas de ejecución del contrato; c) cuántos puntos correspondientes a la fase de adjudicación puede «permitirse» asignar del órgano contratante. Ello variará según los productos/servicios y las condiciones del mercado ${ }^{70}$.

En definitiva, no existe un planteamiento abstracto que permita a priori determinar el valor de ponderación máximo que pueda atribuirse al criterio de adjudicación estratégico, de forma que éste sólo podrá hallarse tras un detenido análisis que, entre otros factores, habrá de tomar en consideración su aptitud para conseguir el objetivo perseguido en el marco de la contratación proyectada.

\section{LA OBLIGADA INTRODUCCIÓN DE CONDICIONES DE EJECUCIÓN DE TIPO ESTRATÉGICO}

\subsection{Experiencias previas: la difícil inteligencia de los límites impuestos por el Derecho social europeo al empleo de condiciones de ejecución de carácter social}

Una herramienta con gran potencialidad para lograr objetivos secundarios en la contratación pública es el establecimiento de obligaciones concretas de cara a la ejecución del contrato. De hecho, el art. 26 de la Directiva 2004/18/CE ya establecía que los poderes adjudicadores podrán exigir condiciones especiales

centaje muy alto de la puntuación total que puede resultar determinante para la adjudicación del contrato». ATAPC Aragón de 30 de agosto de 2016.

66 Vid. ATACP Madrid de 18 de enero de 2017. Los criterios valorables automáticamente eran los siguientes: precio (10 puntos sobre 75), aplicación del convenio estatal durante toda la vigencia del contrato (25 puntos sobre 75) mejora del sistema de remuneración -que incluía el abono del salario en los tres primeros días del mes e incrementos retributivos respecto al convenio estatal (25 puntos sobre 75) y bolsa de horas adicionales (15 puntos). En los términos de la resolución, «[...] en cuanto a la pretendida desproporción de la puntuación alegada incluso si la puntuación otorgada a los criterios mencionados pudiese llevar a considerar que en su aplicación podría convertirse realmente en una condición de ejecución, también como condición de ejecución, este tipo de criterios han sido doctrinalmente admitidos como reconoce expresamente la recurrente».

Vid. igualmente ATACP Madrid de 6 de octubre de 2016 y ATACP Madrid 3 de febrero de 2016.

${ }^{67}$ DOMENCH PASCUAL, G. (2012): "La valoración de las ofertas en el Derecho de los Contratos Públicos", Revista General de Derecho Administrativo, 30.

${ }^{68}$ La ya citada Sentencia Wienstrom el TJUE considera que la atribución de un coeficiente de ponderación del $45 \%$ al criterio de adjudicación ambiental «suministro de energía a través de fuentes renovables» no es en sí misma incompatible con la normativa comunitaria en materia de contratación pública. El límite a la introducción de este tipo de criterios es que no exista una «distorsión injustificada». Y para descartar que en este supuesto esta distorsión se produce constata: a) que se da prioridad al criterio que puede expresarse en cifras, puesto que al criterio del precio se le atribuye un coeficiente superior en diez puntos al atribuido al criterio ambiental: b) que el criterio es útil para la protección del medio ambiente en la medida en que contribuye a reducir las emisiones de gases de efecto invernadero que figuran entre las principales causas de los cambios climáticos que la Comunidad Europea y sus Estados miembros se han comprometido a combatir; c) que la importancia del objetivo perseguido está reconocida por el Derecho de la Unión Europea, en concreto en la Directiva 2001/77.

69 ALONSO GARCÍA C. (2017), "Contratación pública ecológica”, en GAMERO CASADO/GALLEGO CÓRCOLES (dirs.), Tratado de Contratos del Sector Público, Tirant Lo Blanch (en prensa).

70 Manual de Adquisiciones..., pág. 45. Se señala así que por ejemplo, si el grado de variación de los precios relativos a un producto es bajo, pero el rendimiento medioambiental varía enormemente, tiene sentido asignar más puntos para evaluar las características medioambientales. 
en relación con la ejecución del contrato siempre que éstas sean compatibles con el Derecho comunitario y se indiquen en el anuncio de licitación o en el pliego de condiciones, en clara recopilación de la doctrina de la sentencia Beentjes. Además, añadía el precepto, «las condiciones en que se ejecute un contrato podrán referirse, en especial, a las consideraciones de tipo social y medioambiental». En este sentido, se ha afirmado que condiciones de ejecución del contrato constituyen, generalmente, la etapa más apropiada del procedimiento para incluir aspectos sociales relacionados con cuestiones de empleo y condiciones laborales de los trabajadores involucrados en la ejecución del contrato ${ }^{71}$.

Por todo ello, no dejó de sorprender que la STJUE de 3 de abril de 2008, asunto C-346/06, Rüffert, considerase incompatible con el Derecho de la Unión una condición de ejecución relativa al salario de los trabajadores que debía emplear la empresa adjudicataria. En efecto, la sentencia analiza si es compatible con el Derecho europeo la norma de un Land alemán según la cual los contratos de obras sólo podrán adjudicarse a las empresas que en la licitación se comprometiesen por escrito a pagar a sus trabajadores, como mínimo, la retribución establecida en el convenio colectivo aplicable en el lugar de la prestación de tales servicios. Pues bien, el Tribunal europeo consideró esa cláusula inadmisible, ya que el art. 8 Directiva 96/71/CE sobre el desplazamiento de trabajadores efectuado en el marco de una prestación de servicios sólo permite establecer salarios mínimos por referencia a convenios colectivos cuando estos tengan alcance general. Dado que el convenio aplicable en el asunto controvertido se refería exclusivamente a «Edificios y Obras Públicas», el TJUE concluye que no se trata de un convenio de tal naturaleza. De esta forma, el Tribunal al fijar el término de referencia -sector de la construcción, en lugar de sector de la obra pública- no opera, ni mucho menos, con excesiva generosidad. En definitiva, en la argumentación de la sentencia Rüffert no se emplea referencia alguna a la normativa sobre contratación pública, que probablemente hubiera permitido abordar esta problemática adoptando una solución distinta ${ }^{72}$. Baste recordar que el considerando 34 de la Directiva 2004/18/CE consideraba expresamente la normativa social aplicada como una regulación de mínimos ${ }^{73}$.

Sea como fuere, la Directiva 2014/24/UE amplía la referencia a las condiciones de ejecución del contrato, ya que según el art. 70 , «los poderes adjudicadores podrán establecer condiciones especiales relativas a la ejecución del contrato, siempre que estén vinculadas al objeto del contrato en el sentido del art. 67, apartado 3, y se indiquen en la convocatoria de la licitación o en los pliegos de la contratación. Dichas condiciones podrán incluir consideraciones económicas o relacionadas con la innovación, consideraciones de tipo medioambiental, social o relativas al empleo». Dado el tenor del precepto, podría resultar discutible que a través de la nueva Directiva se pretenda superar la doctrina establecida en la sentencia Rüffert y confirmada en la posterior Bundesdruckerei ${ }^{74}$. Y es que la Directiva 2014/24/UE quizá empaña aún más el análisis de la posibilidad de exigir el cumplimiento de todo tipo de convenios colectivos -y no sólo los generales-a través de la inclusión de condiciones de ejecución, ya que desaparece la mención al carácter de normativa

71 Guía para tomar en consideración cuestiones sociales en la contratación pública. SEC (2010) 1258 final, de 19 de octubre de 2010.

72 Comparto en este punto las consideraciones en este punto realizadas por MEDINAARNAIZ (2013: 229 y ss).

73 En concreto, el considerando 34 de la Directiva afirma literalmente que: «las leyes reglamentaciones y convenios colectivos, tanto nacionales como comunitarios, vigentes en materia de condiciones de trabajo y de seguridad del trabajo, se aplicarán durante la ejecución de un contrato público, siempre que dichas normas, así como su aplicación, se ajusten al Derecho comunitario. Para las situaciones transfronterizas, en las que los trabajadores de un Estado miembro prestan sus servicios en otro Estado miembro para la realización de un contrato público, la Directiva 96/71/CE del Parlamento Europeo y del Consejo, de 16 de diciembre de 1996 , sobre el desplazamiento de trabajadores efectuado en el marco de una prestación de servicios, enuncia las condiciones mínimas que han de respetarse en el país de acogida en relación con dichos trabajadores desplazados».

74 La STJUE de 18 de septiembre de 2014, as C-549/13, analiza si es compatible con el Derecho de la Unión determinada norma alemana que impone a los licitadores y a sus subcontratistas que se comprometan a pagar al personal que ejecute las prestaciones objeto del contrato público un salario mínimo. La controversia surge ante la decisión de determinado órgano de contratación de exigir esta condición a un operador económico que tiene intención de subcontratar la ejecución del contrato a una empresa radicada en Polonia, lugar donde exclusivamente va a realizarse la prestación.

EI TJUE concluye que en una situación en la que un licitador tiene previsto ejecutar un contrato público exclusivamente con trabajadores empleados por un subcontratista establecido en un Estado miembro distinto del de la entidad adjudicadora, el artículo 56 TFUE se opone a la aplicación de una normativa del Estado miembro de esa entidad adjudicadora que obliga a ese subcontratista a pagar a los citados trabajadores un salario mínimo fijado por dicha normativa. La doctrina contenida en esta sentencia se ha incorporado al cdo 38 de la directiva, según el cual debe considerarse que los servicios se prestan en el lugar en el que se ejecutan las prestaciones características. Cuando los servicios que se presten a distancia, por ejemplo, servicios prestados por centros de atención telefónica, debe considerarse que dichos servicios se prestan en el lugar en el que se realizan los servicios, con independencia de los lugares y Estados miembros a los que se dirijan los servicios.

En el ámbito del Derecho interno, vid. RRTARCM 12 de junio de 2015 (rec. 83/2015 y 84/2015). 
de mínimos que la Directiva 96/71/CE tenía en el considerando 34 de la Directiva 2004/18/CE ${ }^{75}$. Sobre esta cuestión, se insiste en el considerando 98 de la Directiva 2014/24/UE.

No obstante, la posterior, la STJUE de 17 de noviembre de 2015, RegioPost, asunto C-115/2014 permite una interpretación más generosa del nuevo marco legal. Esta sentencia consideró admisible una condición de ejecución relativa a salarios mínimos, fijada por una disposición legal para todos los contratos públicos en el ámbito territorial de un determinado Land. Aunque la sentencia encierra ciertas ambigüedades, de la misma puede advertirse también una tendencia a la superación de la que se ha llamado «jurisprudencia comunitaria antisocial» del bienio 2007-2008 en la que se incluiría la sentencia Rüffert ${ }^{76}$. De especial importancia es su apartado 65, según el cual, «la limitación del ámbito de aplicación de la norma nacional a los contratos públicos es la mera consecuencia del hecho de que existen normas de Derecho de la Unión que son específicas en este ámbito, en el presente caso las previstas en la Directiva 2004/18 ${ }^{77}$. A partir del mismo se puede defender la posibilidad de establecer unas condiciones laborales más exigentes en el ámbito público.

En nuestro Derecho, en un primer momento este tipo de dificultades interpretativas se plantearon en relación con dos normas reglamentarias que, a través de la utilización de cláusulas sociales, pretendían contrarrestar los efectos de la reforma laboral, en especial las facilidades dadas para los «descuelgues laborales» ex art. 83.2 ET. En concreto se trata de la Norma Foral 4/2013, de 17 de julio de incorporación de cláusulas sociales en los contratos de obras del Sector Público Foral, aprobada por las Juntas Generales de Gipuzkoa ${ }^{78}$, y de la Norma Foral 1/2014, de 12 de febrero, aprobada por las Juntas Generales de Álava para la incorporación de cláusulas sociales en los contratos de obra del sector público foral. Ambas normas incluyen contenidos muy similares. Y mientras la segunda de estas normas es anulada por motivos competenciales (STS de 23 de mayo de 2016, rec. 1383/2015) ${ }^{79}$, la STS de 2 de junio de 2016 (852/2015), confirma la legalidad de la primera. En este sentido la sentencia considera que no se ha justificado por qué ha de impedir la libre competencia la inclusión en los pliegos de los contratos de cláusulas sociales a que alude la norma foral ni las condiciones derivadas del convenio del lugar, aplicable como regla ${ }^{80}$.

En el ámbito de la doctrina de los Tribunales de Recursos Contractuales, han existido igualmente divergencias interpretativas. Así, la RTACP Aragón de 14 de julio de 2016 (Rec. 64/2016) admite la legalidad de la exigencia de mantener la retribución de los trabajadores durante la ejecución del contrato ${ }^{81}$ y en una línea similar, ya que considera válida la exigencia de aplicar el convenio colectivo estatal de referencia se ha pronunciado la RTACR Madrid de 5 de julio de 2017 (rec. 179/2017). Considera inválida dicha cláusula, sin embargo, la RTACRC de 21 de julio de 2017 (rec. 553/2017).

Por lo demás, otra cuestión que se ha planteado con carácter recurrente es la posibilidad de que los pliegos imponga como condición de ejecución la subrogación del personal de la adjudicataria saliente, cues-

75 Así, según el considerando 37 de la nueva Directiva, «las medidas pertinentes se deben aplicar de conformidad con la Directiva 96/71/CE del Parlamento Europeo y del Consejo y de una forma que garantice la igualdad de trato y no discrimine, directa o indirectamente, a los operadores económicos y a los trabajadores de otros Estados miembros».

76 Vid. MOLINA NAVARRETE, C. (2016), "Cláusulas sociales, contratación pública: del problema de su «legitimidad» al de sus «limites», Temas Laborales, 135. pág. 88.

77 Vid. MOLINA NAVARRETE, C. (2016: 86). En el mismo sentido, VÁZQUEZ LACUNZA E. (2016), "El pago de un salario mínimo como condición especial de ejecución en los contratos públicos. Comentario a la STJUE en el caso Regio Post”, Contratación Administrativa Práctica, 146. En relación con dicha sentencia, vid. igualmente MORCILLO MORENO J. (2016), "Las cláusulas sociales en la contratación pública como garantía frente al dumping social intracomunitario", Revista Aragonesa de Administración Pública, 47-48.

78 Mediante esta norma se exige a todos los contratistas y subcontratistas que en la ejecución del contrato respeten las condiciones de trabajo establecidas en el Convenio Colectivo de la Construcción y Obras Públicas de Gipuzkoa o de los sucesivos convenios que los revisen (art. 5). Esta previsión supone que deben respetarse los costes salariales. De hecho dicha norma establece como parámetro para que las ofertas sean consideradas desproporcionadas que la cuantía del precio ofertado sea inferior a dichos costes.

79 Señala la sentencia que parece claro que al encontrarnos ante una disposición de carácter general es evidente que la normativa que se contiene en la disposición objeto de recurso no es una simple aplicación de la normativa contractual por parte de las Juntas Forales de Álava sino ante un desarrollo de la legislación básica del Estado para lo que la competencia corresponde exclusivamente a la Comunidad Autónoma, de conformidad con el artículo 11.1.b del estatuto de Autonomía del País Vasco, en tanto que los Territorios Históricos sólo tiene competencia para desarrollar la legislación básica del Estado en aquellas materias que tienen competencia exclusiva, con exclusión competencial de la Comunidad Autónoma, artículo 7.d Ley 27/83 de Territorios Históricos y Disposición Adicional Segunda de la LBRL.

Previamente, la STS de 25 de noviembre de 2015 (rec. 3405/2014) había confirmado la invalidez de la la Instrucción del Consejo de Gobierno de la diputación de Vizcaya de 29 de octubre de 2013 sobre Criterios de Mantenimiento de las Condiciones de Trabajo y Medidas de Carácter Social para su aplicación en los procedimientos de contratación.

80 La anulación de determinados aspectos de la norma que no afectan en lo esencial a los límites de este estudio, no obstante, fue confirmada 31 de mayo de 2016 (rec. 850/2015).

81 Vid. Igualmente Informe JCCA Aragón 16/2014. 
tión que ha sido zanjada por la STS de 23 de enero de 2017 (rec. 18754/2015) que considera inválida dicha posibilidad ${ }^{82}$.

Finalmente, en otras ocasiones la condición de ejecución incide en las contrataciones que eventualmente deba realizar la empresa para la ejecución del contrato. Así, la RTARC Andalucía de 23 de julio de 2015 (rec. 92/2015) admite la validez de una condición de ejecución que impone que en caso de que se produzcan nuevas contrataciones de personal, estás deberán ser de mujeres hasta determinado porcentaje. Igualmente exige tanto la conversión de los contratos de duración determinada de personal objeto eventualmente de subrogación con carácter estable ${ }^{83}$. Por su parte, la RTCPC Madrid de 6 de octubre de 2016 (rec. 219/2016) confirma legalidad de un pliego que establece como condición especial de ejecución que durante la ejecución del contrato la empresa adjudicataria deberá cumplir y acreditar para las nuevas contrataciones, bajas o sustituciones, que al menos el $30 \%$ de las mismas es indefinida.

\subsection{La nueva regulación de la LCSP: la obligatoriedad de incluir en cada licitación condiciones de ejecución de carácter estratégico}

Como ya hemos señalado, la visión estratégica de la contratación pública ha de integrarse necesariamente en todo procedimiento de contratación (art. 1.3 LCSP). También hemos destacado que este mandato se concreta en el art. 202.1 LCSP ${ }^{84}$, precepto que, de forma totalmente novedosa, establece como obligatorio el establecimiento en el pliego de cláusulas administrativas particulares de al menos una condición que se refiera a consideraciones relacionadas con la innovación, de tipo medioambiental o de tipo social ${ }^{85}$. De esta forma, el legislador español adopta una óptica mucho más ambiciosa que la plasmada en la Directiva 2014/24/UE ${ }^{86}$. Es preciso además destacar que todas las condiciones especiales de ejecución que formen parte del contrato serán exigidas igualmente a todos los subcontratistas que participen de la ejecución del mismo (art. 202.4 LCSP).

Por lo demás, de forma paralela a la regulación de los criterios de adjudicación, la norma introduce un elenco no exhaustivo de condiciones de ejecución ambientales y sociales que podrán incluirse en los procedimientos de contratación.

Así, señala el art. 202.2 LCSP que se podrán establecer, entre otras, consideraciones de tipo medioambiental que persigan: la reducción de las emisiones de gases de efecto invernadero, contribuyéndose así a dar cumplimiento al objetivo que establece el artículo 88 de la Ley 2/2011, de 4 de marzo, de Economía Sostenible; el mantenimiento o mejora de los valores medioambientales que puedan verse afectados por la ejecución del contrato; una gestión más sostenible del agua; el fomento del uso de las energías renovables; la promoción del reciclado de productos y el uso de envases reutilizables; o el impulso de la entrega de productos a granel y la producción ecológica.

Por su parte, el art. 202.2 LCSP dispone que las consideraciones de tipo social o relativas al empleo, podrán introducirse, entre otras, con alguna de las siguientes finalidades: hacer efectivos los derechos re-

82 Sobre esta cuestión, en detalle, vid. HERNÁIZ SALGUERO (2017). Como explica dicha autora, no puede desconocerse que la imposición de una obligación tal puede suponer una importante desventaja competitiva para las pequeñas y medianas empresas que se hallan en peor condición para desarrollar determinadas políticas de personal.

${ }^{83}$ Vid. igualmente RTACRC Andalucía de 15 de julio de 2015 (rec. 93/2015).

84 Este artículo no constaba en el proyecto de Ley. La Ponencia ha aprobado por unanimidad un nuevo texto en relación con este artículo en los términos del Anexo al presente Informe, como consecuencia de la aceptación de la enmienda 911 del GP Mixto-PDeCAT y de la enmienda transaccional procedente de las enmiendas 142 del GP Confederal de Unidos Podemos-En Comú Podem-En Marea, 667, 668, 669, 670 y 671 del GP Socialista, 384 del GP Ciudadanos, 293 del GP de Esquerra Republicana y 912 del GP Mixto-PDeCAT.

85 En todo caso, ha de advertirse que la redacción del segundo apartado del art. 202.1 no es especialmente afortunada, ya que introduce una remisión apartado 202.2 LCSP cuando hubiera sido preferible introducir una referencia directa a las condiciones de ejecución obligatorias. Y es que, como veremos en el art. 202.2 se mencionan «consideraciones económicas, relacionadas con la innovación», «de tipo ambiental» o «de tipo social», pero sólo se enumeran obligaciones relativas a los dos primeros tipos mencionados.

${ }^{86}$ Así, el considerando 123 de la Directiva afirma literalmente que «ante las grandes diferencias existentes entre los distintos sectores y mercados, no sería apropiado imponer a la contratación unos requisitos medioambientales, sociales y de innovación de carácter general y obligatorio.

El legislador de la Unión ya ha establecido unos requisitos de contratación obligatorios para la obtención de objetivos específicos en los sectores de los vehículos de transporte por carretera (Directiva 2009/33/CE del Parlamento Europeo y del Consejo (16)) y los equipos ofimáticos [Reglamento (CE) no 106/2008 del Parlamento Europeo y del Consejo (17). Por otro lado, la definición de métodos comunes para el cálculo de los costes del ciclo de vida ha progresado considerablemente».

En todo caso, como reconoce la Comunicación ya citada «Conseguir que la contratación pública funcione en Europa y para Europa» (pág. 9), para conseguir resultados óptimos en contratación pública deben aplicarse de forma sistemática. 
conocidos en la Convención de las Naciones Unidas sobre los derechos de las personas con discapacidad; contratar un número de personas con discapacidad superior al que exige la legislación nacional; promover el empleo de personas con especiales dificultades de inserción en el mercado laboral, en particular de las personas con discapacidad o en situación o riesgo de exclusión social a través de Empresas de Inserción; eliminar las desigualdades entre el hombre y la mujer en dicho mercado, favoreciendo la aplicación de medidas que fomenten la igualdad entre mujeres y hombres en el trabajo; favorecer la mayor participación de la mujer en el mercado laboral y la conciliación del trabajo y la vida familiar; combatir el paro, en particular el juvenil, el que afecta a las mujeres y el de larga duración; favorecer la formación en el lugar de trabajo; garantizar la seguridad y la protección de la salud en el lugar de trabajo y el cumplimiento de los convenios colectivos sectoriales y territoriales aplicables; medidas para prevenir la siniestralidad laboral; otras finalidades que se establezcan con referencia a la estrategia coordinada para el empleo, definida en el artículo 145 del Tratado de Funcionamiento de la Unión Europea; o garantizar el respeto a los derechos laborales básicos a lo largo de la cadena de producción mediante la exigencia del cumplimiento de las Convenciones fundamentales de la Organización Internacional del Trabajo, incluidas aquellas consideraciones que busquen favorecer a los pequeños productores de paises en desarrollo, con los que se mantienen relaciones comerciales que les son favorables tales como el pago de un precio mínimo y una prima a los productores o una mayor transparencia y trazabilidad de toda la cadena comercial.

La mayor parte de estas condiciones de ejecución no resultan cuestionables, y de hecho algunas de ellas se recogen en el considerando 98 de la Directiva 2014/24/UE ${ }^{87}$. En todo caso, la condición que pudiera resultar más controvertida, según ha sido analizado supra, es la relativa al cumplimiento de los convenios colectivos sectoriales y territoriales aplicables. Y es que, según la nueva Ley, y en la línea que han venido mantiendo algunos tribunales de recursos contractuales autonómicos, es posible que el contrato protega las condiciones laborales de los trabajadores destinados a la ejecución del contrato frente a las posibilidades de «descuelgue del convenio» que permite nuestra legislación laboral. En este sentido, interesa destacar que las tres enmiendas aprobadas en el Senado pretendían sustituir la dicción «convenios colectivos sectoriales» por «convenios colectivos aplicables» en tres preceptos diferentes, entre ellos en el artículo que estamos glosando. De hecho se argumentaba que no podría establecerse que una empresa haya de cumplir lo establecido en el convenio sectorial si cuenta con un convenio colectivo propio ${ }^{88}$. El posterior rechazo de estas tres enmiendas en el Congreso permite disipar cualquier género de dudas sobre el hecho de que en el ámbito de la contratación pública las condiciones mínimas que deben ser garantizadas a los trabajadores son las establecidas en el convenio sectorial y no en el convenio de empresa.

Frente a las dudas que se han podido suscitar, no creo que esta nueva regulación vulnere el Derecho europeo, como tampoco lo hacían, a mi juicio, el ATACP Aragón de 14 de julio de 2016 y la RTACR Madrid de 5 de julio de 2017 que admitían soluciones similares. Y ello por dos tipos de razones. En primer lugar, este tipo de cláusulas no sólo no limitan la competencia, sino que garantizan el principio de igualdad ${ }^{89}$, ya que la ultra-actividad de los convenios produciría una alteración de las condiciones de la adjudicación, quebrándose a la vez el principio de equivalencia de las prestaciones. Pero en segundo lugar, dado nuestro contexto normativo, precisamente admitir que las empresas puedan abonar salarios por debajo del convenio sectorial vigente puede implicar una ventaja competitiva para las empresas nacionales difícilmente aceptable por el Derecho Europeo. Y es que sólo las empresas europeas que desplazasen trabajadores se verían obligadas a abonar como mínimo el salario del convenio sectorial correspondiente ${ }^{90}$. Al margen de todo lo anterior, no puede olvidarse que la precarización de las condiciones laborales repercute negativamente en la calidad de la prestación ${ }^{91}$.

87 Según éste, «condiciones de ejecución de un contrato pueden tender también a favorecer la aplicación de medidas que fomenten la igualdad entre mujeres y hombres en el trabajo, la mayor participación de la mujer en el mercado laboral y la conciliación del trabajo y la vida familiar, la protección medioambiental o animal, respetar en lo sustancial los convenios fundamentales de la Organización Internacional del Trabajo (OIT) y contratar un número de personas discapacitadas superior al que exige la legislación nacional»

$88 \mathrm{Vid}$. Enmienda 255. Esta misma cuestión es la que se late en la enmienda 253, en relación con el establecimiento en el pliego de la obligación del adjudicatario de cumplir las condiciones salariales del los trabajadores establecida en el art. 122 y la enmienda 254 , referente a presunción de temeridad de la oferta. Las tres enmiendas fueron rechazadas en el Congreso.

89 Vid. En este sentido, vid. ATACP Aragón de 14 de julio de 2016 (Rec. 64/2016).

90 Vid. art. 3 Directiva 96/71/CE del Parlamento Europeo y del Consejo de 16 de diciembre de 1996 sobre el desplazamiento de trabajadores efectuado en el marco de una prestación de servicios.

91 Sobre esta cuestión insiste la RTCPC Madrid de 6 de octubre de 2016 (rec. 219/2016). Se afirma así que el órgano de contratación ha puesto de relieve la existencia de circunstancias que pueden poner en entredicho la ejecución del contrato como consecuencia del bajo nivel salarial que se satisface a los trabajadores por debajo del precio del convenio del sector, explicando la peculiar situación 
En todo caso, en relación con la nueva regulación de las condiciones de ejecución quizás el aspecto que resulte más criticable es el relativo a la regulación del incumplimiento de estas condiciones de ejecución, pues la posibilidad de establecer penalidades, resolver el contrato o establecer una prohibición para contratar ex letra c) del apartado 2 del artículo 71 dependerá de lo que establezcan a estos efectos los pliegos. Pues bien, la introducción de mecanismos de control y la regulación de las consecuencias del incumplimiento debiera ser un elemento preceptivo en todos los pliegos. Como señalara el IJCCA Aragón 1/2015, de 17 de marzo, resulta insolayable que la cláusulas en cuestión incorporen los necesarios parámetros objetivos para determinar cuando la obligación se entiende cumplida, debíendose establecerse un importante y responsable control por la Administración en la fase de ejecución del contrato. De otro modo, la efectividad de la cláusula quedaría a expensas de la buena voluntad del contratista.

\section{LAS HERRAMIENTAS PROCEDIMENTALES AL SERVICIO DE LA INNOVACIÓN: EN ESPECIAL, LA ASOCIACIÓN PARA LA INNOVACIÓN}

La Directiva 2004/18/CE, como se ha señalado, no emplea el término innovación. Frente a ello, el concepto de innovación aparece con reiteración en la Directiva 2014/24/UE, uno de cuyos objetivos, recuérdese, es permitir que los compradores utilicen mejor la contratación pública como apoyo, entre otras políticas, de la promoción de la innovación. Todo ello en un contexto en el que la Comisión había puesto de manifiesto que a pesar de las oportunidades que ofrecía el marco legal europeo, distintos factores entre los que se encuentran la falta de incentivos, la aversión al riesgo, un conocimiento insuficiente y falta de capacidad de liderazgo llevaba a las autoridades públicas a ser muy cautas a la hora de incorporar soluciones innovadoras ${ }^{92}$. Y ello, pese el carácter central de la innovación en la Estrategia 2020.

La nueva Directiva, por tanto, pretende vencer las resistencias existentes. Y aunque la tarea de definir innovación no es en absoluto sencilla ${ }^{93}$ su artículo 2.1.22 incorpora el concepto de innovación ${ }^{94}$ que es definido como «introducción de un producto, servicio o proceso nuevos o significativamente mejorados, que incluye, aunque no se limita a ellos, los procesos de producción, edificación o construcción, un nuevo méto-

del sector de la seguridad en España, con reducción de los salarios en una media del $30 \%$ por mor del descuelgue del Convenio sectorial, a través de convenios que vienen siendo sistemáticamente anulados en la jurisdicción laboral.

A todo ello cabe añadir que la precariedad salarial, con carácter general es generadora de conflictos que pueden hacer peligrar la consecución del objeto del contrato y que en un momento de repunte de la actividad económica se produce aun otro efecto pernicioso en relación con la ejecución contractual, y es que la oferta de mejores salarios en otras empresas puede «vaciar» de personal contratos en ejecución, con la dificultad de sustituir el personal.

92 SEC (2011) 1585 final, 83. Vid. igualmente Comunicación de la Comisión Iniciativa emblemática de Europa 2020, Unión por la innovación, COM (2010) 546 final, de 6 de octubre de 2010, en cuya página 7 puede leerse que: «la lentitud de la normalización y la incapacidad de hacer un uso estratégico de la contratación pública desalientan la inversión privada en investigación e innovación e impiden que las ideas lleguen al mercado» (pág. 7). En la página 16 puede leerse «la contratación pública de productos y servicios innovadores es vital para mejorar la calidad y la eficiencia de los servicios públicos, en un momento de restricciones presupuestarias. No obstante, en Europa son pocos los contratos públicos que tienen por objeto la innovación, a pesar de las oportunidades que ofrecen las directivas de contratación de la UE. Esto se debe a una serie de factores, como son: incentivos que van en favor de soluciones de poco riesgo; ausencia de conocimientos y capacidades con respecto a la contratación apropiada de nuevas tecnologías e innovaciones; y desconexión entre los contratos públicos y los objetivos de las políticas. Esta cuestión puede abordarse mejor mediante directrices e intercambio de las mejores prácticas, concretamente en el ámbito de la contratación pública verde. Por otro lado, como los mercados de contratación pública siguen estando fragmentados en toda Europa, a menudo los contratos no consiguen alcanzar la escala crítica necesaria para poner en marcha inversiones innovadora».

93 Como explican GRANIERI y RENDA (2012): Innovation Law and Policy in the European Union: Towards Horizon 2020, Springer, pág. 3, las definiciones clásicas de innovación -por ejemplo, el proceso a través del cual los individuos y organizaciones generan nuevas ideas y las llevan a la práctica- resultan demasiado estrictas, especialmente si se observa la dinámica peculiar de la innovación hoy y su probable evolución en los próximos años. Y es que los mercados y las formas de intercambio cambian continuamente, a menudo separándose de la cadena tradicional de actividades innovadoras que tenía lugar principalmente en universidades y en grandes laboratorios públicos y privados. Hasta tal punto, que ciertas corrientes escépticas sostienen que la innovación es hoy en día imposible de definir.

En este sentido, los autores (pág. 4) sostienen que una definición clara de innovación y de su papel en la economía moderna es esencial para el diseño de políticas inteligentes, sostenibles e innovadoras. Y proponen que la innovación se defina como la creación de un nuevo (o asignación eficiente de un existente) recurso que contribuya al progreso. Como explican, el primer elemento, el elemento ontológico se incluye en el sentido más amplio posible, dando cabida, entre otros, a la innovación generada por el usuario, proyectos industriales de I+D, inversión pública. El elemento teológico simplemente constata que un nuevo producto sólo será considerado innovación en la medida en la que contribuya al bienestar social a largo plazo, sin privar a la sociedad de recursos que podrían ser más útilmente asignado en otro lugar. De manera telegráfica, los principales rasgos de la innovación son la distribución eficiente y el progreso.

${ }^{94}$ Este concepto no ha sido objeto de trasposición en la LCSP. 
do de comercialización o un nuevo método de organización de prácticas empresariales, la organización del lugar de trabajo o las relaciones exteriores, entre otros con el objetivo de ayudar a resolver desafíos de la sociedad o a apoyar la Estrategia Europa 2020 para un crecimiento inteligente, sostenible e integrador» ${ }^{95}$.

En este contexto, una de las principales novedades de la Directiva 2014/24/UE es la creación de un procedimiento de contratación específico que permite establecer una asociación para la innovación a largo plazo con vistas al desarrollo y la ulterior adquisición de nuevos productos, servicios u obras innovadores. El nuevo procedimiento se caracteriza por abarcar tanto la fase de investigación y desarrollo como la de la adquisición de los resultados obtenidos, estructurando así un procedimiento competitivo específicamente diseñado para tal fin ${ }^{96}$. De esta forma, la asociación para la innovación, en su primera fase (precomercial), se equipara a la una contratación precomercial de grado mínimo, puesto que la tecnología buscada o ya existe -y pretende mejorar- o es factible desarrollarla con éxito en breve plazo. Pero en su segunda etapa (comercial o contractual) la naturaleza del contrato vendrá determinada por el tipo de producto final requerido por el órgano de contratación (suministros, servicios u obras resultantes) ${ }^{97}$. Por ello, como se ha señalado, la asociación para la innovación ${ }^{98}$ abarca tres etapas diferentes ${ }^{99}$ :

a) El desarrollo del procedimiento de adjudicación de la asociación para la innovación que conduce a la elección del socio/socios que participaran en la fase de innovación.

b) La fase de innovación en sí misma.

c) La adquisición del resultado de la fase de innovación.

La LCSP dedica los artículos 177 a 182 regular la asociación para la innovación. Tal y como dispone el art. 177 LCSP, la finalidad del procedimiento es «la realización de actividades de investigación y desarrollo respecto de obras, servicios y productos innovadores» y la compra ulterior de los suministros, servicios u obras resultantes, cuando se alcancen los niveles de rendimiento y los costes máximos acordados entre los órganos de contratación y los participantes.

Ente las especificidades del procedimiento de adjudicación destaca el hecho de que en los pliegos de cláusulas administrativas particulares de la contratación el órgano de contratación determinará «la necesidad de un, servicio y obra innovadores que no pueda ser satisfecha mediante la adquisición de productos,

95 Para CERQUEIRA GOMES, P. (2014): "The Innovative Innovation Partnerships Under the 2014 Public Procurement Directive", Public Procurement Law Review (PPLR), Issue 4, pág. 213] la definición del art. 31 de la Directiva -en el ámbito del procedimiento de asociación para la innovación-no coincidiría exactamente con la establecida en el art. 2.22, estableciendo así la norma dos definiciones distintas no siempre conciliables, ya que mientras en el segundo caso la definición sólo incluiría ontológica -creación de algo nuevo-, en la segunda se añadiría un elemento teleológico -contribución al bienestar social-. De esta forma, la Directiva crearía cierta inseguridad jurídica.

En mi opinión, añadir el elemento teológico en al art. 31 de la Directiva hubiera sido reiterativo.

96 Desde el punto de vista de las obligaciones internacionales asumidas por la Unión europea es preciso distinguir los contratos de servicios de investigación de los de adquisición de los resultados. En este sentido, en el ámbito de la Unión europea se entendió que el desarrollo de las actividades de investigación y desarrollo requiere más flexibilidad que la establecida en los rígidos procedimientos impuestos por el Acuerdo sobre Contratación Pública de la OMC de forma que la Unión Europea ha excluido del mismo los contratos de servicios de investigación y desarrollo -pero no los contratos de suministro del producto/servicio desarrollado que eventualmente seguirían al mismo-

97 LOPEZ MIÑO, "La compra pública innovadora en los sistemas europeo y español de contratación pública" en J. PERNAS GARCíA (Dir.), ob. cit., pág. 233. Y así en el art. 177 LCSP se distingue entre la fase de investigación y desarrollo, regida supletoriamente por las normas de contrato de servicios y la fase de ejecución de obras, servicios o suministros, regida por las normas correspondientes al contrato relativo a la prestación de servicios que se trate. Y es que, en definitiva, el objeto de la asociación para innovación es complejo: por un lado comprende el propio de un contrato de servicios de investigación y, por otro, eventualmente, una obra, un suministro o servicio innovador que es el resultado del contrato de servicios anterior.

98 FERNÁNDEZ SCAGLIUSI, M. A. (2015): "Un nuevo procedimiento de adjudicación de contratos públicos: la asociación para la innovación", en el vol. col. J. M. GIMENO FELIU (Dir.), Las nuevas Directivas de contratación pública, Observatorio de Contratos públicos, Thomson Reuters Aranzadi;. RODRIGUEZ BEAS, B. (2015): "La compra pública innovadora en la nueva Directiva de contratación pública", en libro colectivo Las Directivas de Contratación Pública, número monográfico especial Observatorio de los Contratos Públicos 2014, Aranzadi, Cizur Menor, 2015, págs. 305-328. VALCÁRCEL FERNÁNDEZ P. (2017): "La Compra Pública de Innovación (CPI). El procedimiento de adjudicación de Asociación para la Innovación" en GAMERO CASADO/GALLEGO CÓRCOLES (dirs.) Tratado de Contratos del Sector Público, Tirant Lo Blanch (en prensa). BERNAL BLAY, M. Á. (2017): "Comentario a los artículos 177 a 182 de la LCSP", en el libro de Comentarios a la nueva Ley de Contratos del Sector Público, El Consultor de los Ayuntamientos y de los Juzgados, (en prensa); HERNANDO RYDINGS, M. (2017): "El procedimiento de asociación para la innovación", en Estudio sistemático de la ley contratos sector publico, Aranzadi (dir.). J. M. GIMENO FELIÚ, Aranzadi (en prensa): TARDíO PATO, J. A. (2016): "La Asociación para la innovación" como contrato y como procedimiento de adjudicación", en Observatorio de los Contratos Públicos 2015, Thomson Reuters Aranzadi, Cizur Menor.

${ }^{99}$ CERQUEIRA GOMES (2014: 212). 
servicios y obras ya disponibles en el mercado». Es decir, frente a la compra ordinaria, donde se determina un concreto objeto, en este procedimiento se prevé una necesidad. Motivo por el que no existe un PTT clásico, sino un pliego de prescripciones funcionales ${ }^{100}$.

Por lo demás, el desarrollo del procedimiento de adjudicación se caracteriza porque al igual que el procedimiento restringido, existe una fase de selección de candidatos. Los órganos de contratación podrán limitar el número de candidatos aptos que hayan de ser invitados a participar en el procedimiento, siendo tres el número mínimo (art. 178 LCSP). También existe una fase de negociación, en la que los candidatos presentarán sus proyectos de investigación e innovación para responder a las necesidades a cubrir. Los contratos se adjudicarán únicamente con arreglo al criterio de la mayor calidad-precio (art. 179. 2 LCSP). Es decir, el socio o socio que forme parte de la fase de investigación e innovación será elegido con arreglo a criterios económicos y cualitativos.

En segundo lugar, tal y como se desprende del art. 180 LCSP, la fase de investigación e innovación se estructurará en fases sucesivas siguiendo la secuencia lógica de las etapas del proceso de investigación e innovación. En el contrato o contratos que se suscriban con los socios que participen en ella se fijarán unos objetivos intermedios que deberán alcanzar y se proveerá el pago de una retribución en plazos adecuados.

Finalmente, concluidas las fases de investigación y desarrollo, el órgano de contratación analizará si los resultados obtenidos en ellas alcanzan los niveles de rendimiento y los costes acordados. Tras dicho análisis resolverá lo procedente acerca de la adquisición de las obras, servicios o suministros innovadores resultantes, que se realizarán en los términos establecidos en el pliego de cláusulas administrativas particulares. En el caso de que la asociación se hubiese estructurado con varios socios, la selección del empresario al que se deba efectuar dichas adquisiciones se realizará sobre las base de los criterios objetivos que se hayan establecido en el pliego ${ }^{101}$.

Como ha destacado GIMENO FELIU ${ }^{102}$, pese a la potencialidad de este nuevo procedimiento, pueden seguir existiendo ciertas resistencias entre las que se pueden citar: el desconocimiento de beneficios económicos y sociales; la ausencia de claridad jurídica sobre las posibilidades de realizar la compra de innovación; la falta de información y de herramientas; la aplicación de criterios no uniformes; la falta de un intercambio adecuado de experiencias; la ausencia de profesionalización, y de apoyo político.

Ahora bien, la existencia de estas debilidades no puede implicar la renuncia a al fomento de la innovación a través de otros mecanismos procedimentales. Y es que las posibilidades de introducir innovación no se limitan a este procedimiento complejo y sofisticado, procedimiento que en principio sólo estará al alcance de los órganos de contratación más avezados en investigación e innovación.

Antes al contrario, la innovación puede integrarse en el día a día la contratación pública a través de distintas herramientas. De hecho, antes de elegir el concreto procedimiento a través del cual se quiera dar respuesta a una necesidad pública de forma innovadora, los órganos de contratación tendrán que tomar en consideración aspectos tales grado de conocimiento del mercado, si son necesarios trabajos de investigación y desarrollo, si las especificaciones pueden desarrollarse, si existe necesidad de adquirir la solución a escala comercial, el número de suministradores potenciales y la estructura del mercado, y el tiempo y los recursos disponibles para la licitación ${ }^{103}$. Así, hay que tener en cuenta que, aunque con carácter tendencialmente «preprocedimental», la nueva Ley regula en el art. 115 las consultas preliminares al mercado, herramienta idónea la preparación de procedimientos innovadores en los que los poderes adjudicadores carecen de la experiencia o del conocimiento específico sobre la materia objeto del contrato ${ }^{104}$.

100 Vid. GIMENO FELIU J. M., (2017 b): "Public procurement as an strategy for the development of innovation policy" (en prensa).

101 Finalmente, el artículo 181.3 LCSP establece que cuando la adquisición de las obras, servicios o suministros conlleve la realización de prestaciones sucesivas, aquella sólo se podrá llevar a cabo durante un periodo máximo de cuatro años a partir de la recepción de la resolución sobre la adquisición de las obras, servicios o suministros innovadores.

102 GIMENO FELIU J. M., (2017 b).

103 En este sentido, resulta sumamente interesante el documento Public Procurment Innovation Guidance for Public Authorities, publicado por PROCUREMENT OF INNOVATION PLATFORM, disponible en https://www.innovation-procurement.org/fileadmin/editorcontent/Guides/PPI-Platform Guide new-final download.pdf (fecha de consulta: 10-10-2017).

El documento considera cinco procedimientos relevantes para la compra pública innovadora: consultas preliminares al mercado, compra pública precomercial, procedimiento de licitación con negociación, diálogo competitivo y asociación para la innovación.

104 Vid. MIÑO LÓPEZ A. (2017): Defensa de la competencia y contratación pública, Como señala el autor, la contratación pública innovadora -contratación pre-comercial, compra pública de tecnología innovadora y asociación para la innovación-es la candidata más proclive a acudir a las consultas preliminares al mercado en todos y cada uno de los procedimientos.

Ahora bien, la potencialidad de esta herramienta no debe soslayarse de cara a la introducción de consideraciones ambientales y sociales en la contratación pública. Por ejemplo, puede resultar útil de cara a determinar si, en el ámbito de un procedimiento cualquiera, 
De este modo, en función de los condicionantes mencionados, y del grado de desarrollo en el mercado de la eventual solución innovadora, el órgano de órgano de contratación tiene una serie de herramientas disponibles. Así, tras el carácter flexible con el que la LCSP formula los supuestos de utilización del procedimiento de licitación con negociación y del diálogo competitivo se esconde la pretensión de promover una más amplia utilización de los mismos de cara a favorecer la innovación (vid. art. 167 LCSP) ${ }^{105}$. Es más, en el ámbito de este último procedimiento, la Ley española desarrolla la previsión de la Directiva 2014/24/UE, según la cual los poderes adjudicadores podrán prever primas o pagos para los participantes en el diálogo. Esta medida incentivadora del uso eficaz del diálogo competitivo, prevista ya en el Directiva 2004/18/CE, se reconocía en el art. 179.2 TRLCSP. Pero esta vez el legislador español no se ha limitado a recoger el tenor literal de la norma europea, lo que merece una valoración muy positiva, ya que como señalan TELLES y BULTER, el establecimiento de estas medidas de este tipo puede ayudar a que el diálogo competitivo sea un procedimiento más útil y fácil de emplear ${ }^{106}$.

\section{NOTA FINAL: LA INCORPORACIÓN DE POLÍTICAS AMBIENTALES, SOCIALES Y DE INNOVACIÓN EN LA CONTRATACIÓN PÚBLICA: UN RETO QUE VA MÁS ALLÁ DE LO NORMATIVO}

La nueva LCSP, adoptando un enfoque ostensiblemente más ambicioso que el establecido en la Directiva 2014/24/UE, remueve con decisión los obstáculos normativos que han dificultado la plena integración de las políticas de ambientales y sociales en la contratación pública. También apuesta por medidas orientadas al estímulo de la innovación desde el lado de la demanda y en este ámbito también introduce algún avance significativo respecto al marco europeo.

No obstante, el éxito de todas estas medidas no dependerá exclusivamente de la calidad de la norma, sino fundamentalmente del éxito en su ejecución. Y ello plantea desafíos que van más allá de lo estrictamente jurídico. Será preciso así que exista un alto grado de compromiso político, que se favorezca una contratación menos burocratizada y más profesional ${ }^{107}$, y que se formulen estrategias de contratación claras ${ }^{108}$. No debe desdeñarse la posibilidad de plantear reformas organizativas, dentro de un planteamiento holístico en el seno de cada organización ${ }^{109}$. Y finalmente, la posibilidad de aprender de experiencias previas y de conseguir impactos significativos dependerá de la capacidad de evaluación de las iniciativas desplegadas ${ }^{110}$.

De hecho, la implementación de los Fondos de Inversión Local ${ }^{111}$ demuestra que este tipo de iniciativas deben diseñarse con suficiente pericia. No puede afirmarse que esta experiencia haya resultado totalmente

resulta más idóneo incluir un requerimiento técnico ambiental concreto como especificación técnica o como criterio ambiental, decisión que dependerá en buena medida del número de empresas con capacidad para cumplir dicho requerimiento.

105 En detalle, GALLEGO CÓRCOLES, I. (2017b): "Los procedimientos abierto, restringido, licitación con negociación, negociado sin publicidad y dialogo competitivo", en GIMENO FELIU (dir.), Estudio Sistemático de la Ley de Contratos del Sector Público, Aranzadi (en prensa).

106 TELLES, P. BUTLER, L. (2014): "Public Procurement Award Procedures in Directive 2014/24/EU" en LICHERE, CARANTA and TREUMER (eds.), Novelties in the 2014 Directive on Public Procurement, Djof Publishing, pág. 114. Así lo demuestra la experiencia francesa, donde la legislación de transposición de la Directiva 2004/18/CE ya exigía este este pago cuando el procedimiento de adjudicación conlleve «gastos significativos». Del mismo modo, la experiencia previa en Portugal, a través del procedimiento de licitación con negociación en los que los poderes adjudicadores abonaban hasta cierto valor de los costes de desarrollo de la oferta ha resultado satisfactoria.

107 Vid. GIMENO FELIU (2014), in totum. Sobre ello vid. Recomendación de la Comisión de 3-10-2017, "Construir una arquitectura para la profesionalización de la contratación pública", C(2017) 6654 final. Entre las recomendaciones se encuentra facilitar y fomentar el pensamiento estratégico.

108 Sobre este aspecto insiste la citada Comunicación «Conseguir que la contratación pública funcione en Europa y para Europa», pág. 7. En relación con el ello, el art. 334.2 LCSP establece como uno de los objetivos de la Estrategia Nacional de Contratación Pública «utilizar las posibilidades de la contratación pública para apoyar políticas ambientales, sociales y de innovación».

109 Vid. el Estudio "Strategic use of public procurement in promoting green, social and innovation policies" realizado a instancias de la Comisión Europea, diciembre 2015. Como se afirma en la pág. 98, la contratación pública estratégica comprende tres áreas de políticas públicas diferentes -compra ecológica, compra socialmente responsable y compra innovadora- que están vinculadas de múltiples formas. Sin embargo, muy a menudo dichas políticas se tratan como ámbitos diferenciados y en ello no se implica directamente a los órganos responsables de la contratación pública, que se sienten ajenos a estas políticas públicas.

110 Así, el estudio Estudio "Strategic use of public procurement in promoting green, social and innovation policies" pone de manifiesto que la monitorización representa el área de mayor debilidad de la compra pública estratégica. Y aunque se llevan a cabo iniciativas en los distintos Estados Miembros, a menudo se realiza de forma irregular. De esta forma, es difícil obtener un marco preciso de los resultados de la contratación pública estratégica y aprender lecciones para el diseño de públicas.

111 Como es sabido, el Real Decreto-Ley 9/2008, de 28 de noviembre, crea un Fondo Estatal de Inversión Local y un Fondo Especial para la Dinamización de la Economía y el Empleo y se aprobaron créditos extraordinarios para atender a su financiación. 
feliz y que el importante esfuerzo inversor realizado ${ }^{112}$ haya producido los efectos deseados. El Tribunal de Cuentas ha tenido ya ocasión de analizar estos instrumentos a través de sus informes de 26 de septiembre de 2012, de 25 de abril de 2013 y de 24 de julio de 2014. Y entre otras críticas, se destacan errores de diseño del mecanismo normativo, como por ejemplo que no se exigiese que el criterio de creación de empleo valorase el número de trabajadores nuevos contratados respecto de días ${ }^{113}$. Se detectaron igualmente desviaciones a la baja entre el número de puestos de trabajo comprometidos en la adjudicación del contrato respecto a su ejecución real ${ }^{114}$. Finalmente, en la formulación de los criterios de adjudicación no siempre se respetó los principios de publicidad, transparencia y objetividad ${ }^{115}$.

La práctica demuestra así que una utilización inadecuada de las cláusulas estratégicas no sólo compromete la realización del objetivo político perseguido -en aquel caso, la creación de empleo-, sino también la realización de los principios de igualdad, transparencia y eficiencia (art. 1.1 LCSP de la Directiva). La contratación estratégica es transversal y obligatoria. Pero será preciso valorar cuidadosamente el objetivo a perseguir y elegir el medio idóneo, de forma que se tienda a lograr el deseable equilibrio entre los distintos fines y principios que el procedimiento de licitación ha de armonizar.

Por otro lado, la incorporación de cláusulas estratégicas exige que se realice el consecuente control del cumplimiento efectivo de la cláusula en cuestión durante la fase de ejecución. Y ello, independientemente de la fase en la que esta cláusula entre a formar parte del contenido obligacional pactado. Porque de otro modo, durante la fase de licitación no se llevará a cabo una competencia real, sino meros juegos de ilusión y artificio. De nada sirve el respeto escrupuloso en la fase de adjudicación de los principios de igualdad y transparencia si, tras la conclusión del procedimiento, el cumplimiento de lo ofertado por el licitador (o de lo exigido por el poder público) queda al albur del adjudicatario.

No pretenden estas últimas consideraciones restar valor a la valiente configuración de la vertiente instrumental de la contratación pública como elemento estructurante de la LCSP. Sólo intentan mostrar la complejidad del camino hacia el que la nueva norma dirige la contratación para que pueda transitarse por él con la suficiente seguridad, impulso y decisión.

Posteriormente, el Real Decreto-Ley 13/2009, creó el Fondo Estatal para el Empleo y la Sostenibilidad Local.

112 En virtud del Real Decreto Ley 9/2008 se dispusieron de un total de 11.000 millones de euros con cargo al presupuesto de 2008. El Fondo Estatal para el Empleo y la Sostenibilidad Local se dotó con 5.000 millones de euros.

113 Así que otorgó mayor puntuación a aquellos proyectos que preveían contratar un mayor número de trabajadores nuevos independientemente del número de días.

114 Por ejemplo, en el último de los informes citados se destaca que la estimación inicial de los ayuntamientos del volumen de mano de obra a emplear en la ejecución de los proyectos fue muy inferior al compromiso que posteriormente adoptaron las empresas. Este hecho, se añade, fue consecuencia de la falta de concreción del dato de mano de obra que se debía aportar en la solicitud de la financiación y la inclusión, como estimación, del número mínimo de trabajadores que posteriormente se exigió a los adjudicatarios en los pliegos.

115 Vid. con más detalle, BERNAL BLAY M. A., "El desarrollo de políticas activas de empleo a través de los contratos públicos" en PERNAS GARCÍA (2013), págs. 175 y ss. Igualmente, del mismo autor, "La contratación de desempleados para la ejecución de contratos públicos: Diez conclusiones de la experiencia del Fondo Estatal de Inversión Local creado por Real Decreto-Ley 9/2008", diciembre de 2012, en www.obcp.es. Se mostró ya crítico con este mecanismo GIMENO FELIU J. M. (2010), "Contratación pública y crisis económica", El Cronista, núm. 9. 